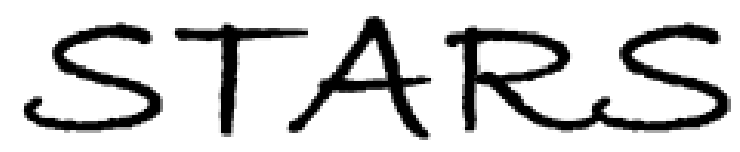

University of Central Florida

STARS

$1-1-2012$

\title{
Challenges to Satellite Sensors of Ocean Winds: Addressing Precipitation Effects
}

\author{
D. E. Weissman \\ B. W. Stiles \\ S. M. Hristova-Veleva \\ D. G. Long \\ D. K. Smith
}

See next page for additional authors

Find similar works at: https://stars.library.ucf.edu/facultybib2010

University of Central Florida Libraries http://library.ucf.edu

This Article is brought to you for free and open access by the Faculty Bibliography at STARS. It has been accepted for inclusion in Faculty Bibliography 2010 s by an authorized administrator of STARS. For more information, please contactSTARS@ucf.edu.

\section{Recommended Citation}

Weissman, D. E.; Stiles, B. W.; Hristova-Veleva, S. M.; Long, D. G.; Smith, D. K.; Hillburn, K. A.; and Jones, W. L., "Challenges to Satellite Sensors of Ocean Winds: Addressing Precipitation Effects" (2012). Faculty Bibliography 2010s. 3475.

https://stars.library.ucf.edu/facultybib2010/3475

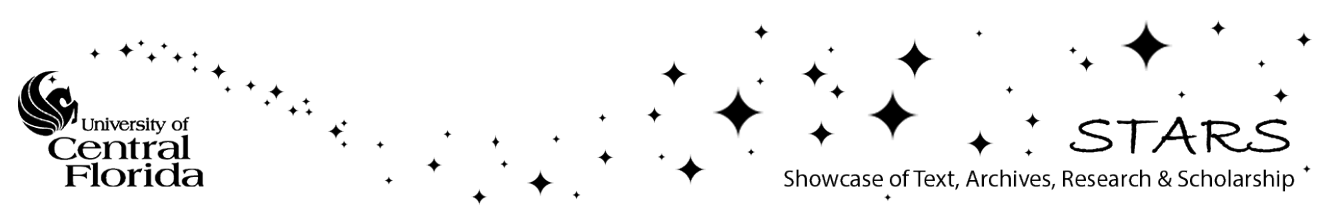




\section{Authors}

D. E. Weissman, B. W. Stiles, S. M. Hristova-Veleva, D. G. Long, D. K. Smith, K. A. Hillburn, and W. L. Jones 


\title{
Challenges to Satellite Sensors of Ocean Winds: Addressing Precipitation Effects
}

\author{
D. E. WEISSMAN \\ Hofstra University, Hempstead, New York \\ B. W. Stiles And S. M. Hristova-Veleva \\ Jet Propulsion Laboratory, California Institute of Technology, Pasadena, California \\ D. G. LONG \\ Center for Remote Sensing, Brigham Young University, Provo, Utah \\ D. K. SMith AND K. A. Hilburn \\ Remote Sensing Systems, Santa Rosa, California \\ W. L. JONES \\ University of Central Florida, Orlando, Florida
}

(Manuscript received 28 March 2011, in final form 8 November 2011)

\begin{abstract}
Measurements of global ocean surface winds made by orbiting satellite radars have provided valuable information to the oceanographic and meteorological communities since the launch of the Seasat in 1978, by the National Aeronautics and Space Administration (NASA). When Quick Scatterometer (QuikSCAT) was launched in 1999, it ushered in a new era of dual-polarized, pencil-beam, higher-resolution scatterometers for measuring the global ocean surface winds from space. A constant limitation on the full utilization of scatterometer-derived winds is the presence of isolated rain events, which affect about $7 \%$ of the observations. The vector wind sensors, the Ku-band scatterometers [NASA's SeaWinds on the QuikSCAT and Midori-II platforms and Indian Space Research Organisation's (ISRO's) Ocean Satellite (Oceansat)-2], and the current C-band scatterometer [Advanced Wind Scatterometer (ASCAT), on the European Organisation for the Exploitation of Meteorological Satellites (EUMETSAT)'s Meteorological Operation (MetOp) platform] all experience rain interference, but with different characteristics. Over this past decade, broadbased research studies have sought to better understand the physics of the rain interference problem, to search for methods to bypass the problem (using rain detection, flagging, and avoidance of affected areas), and to develop techniques to improve the quality of the derived wind vectors that are adversely affected by rain. This paper reviews the state of the art in rain flagging and rain correction and describes many of these approaches, methodologies, and summarizes the results.
\end{abstract}

\section{Introduction}

Scatterometer global ocean surface winds have been providing valuable measurements to oceanographers, meteorologists, and operational forecasters for many years (Attema 1991; Figa-Saldana et al. 2002; AGU

Corresponding author address: David E. Weissman, 201B Weed Hall, Department of Engineering, 133 Hofstra University, Hempstead, NY 11549.

E-mail: eggdew@hofstra.edu
2004). Scatterometers are specialized satellite microwave radars that precisely measure the portion of the transmit power that echoes back (backscatters) from the earth's surface (Spencer et al. 2003). Wind speed and direction are derived from the returned power using a geophysical model function (GMF). These model functions combine data from the various geometric views by the individual antenna(s) and their respective polarizations. They employ empirical relationships between the radar observables and principal geophysical variables at the ocean-atmosphere interface. In the past, 
rain has not been included as a quantitative parameter in these wind vector retrievals, except as a flagged parameter in the final data products.

The SeaWinds scatterometer on the Quick Scatterometer (QuikSCAT) satellite is referred to simply as QuikSCAT both within the community and this document, and was so named to signify the intense "quick recovery" effort after the sudden demise of the National Aeronautics and Space Administration (NASA) Scatterometer (NSCAT) on the Japanese Advanced Earth Observing Satellite (ADEOS)-I mission (launched in September 1996 and expired in June 1997). QuikSCAT gained rapid NASA project approval and was launched in 1999. QuikSCAT operated at $14 \mathrm{GHz}$ and consisted of vertical and horizontal polarization channels (Spencer et al. 2003). Another scatterometer mission, Midori-II, had an unfortunately short lifetime of only 9 months, ending in October 2003 because of a power system failure. Midori-II included both a scatterometer (SeaWinds) and a multifrequency radiometer [Advanced Microwave Scanning Radiometer (AMSR)]. Much was learned from this combination of instruments despite the short time of operation. While QuikSCAT did not include a radiometer, it lasted more than $10 \mathrm{yr}$ (until its antenna stopped spinning in November 2009) and provided high-quality data to a wide variety of scientific users. This decade-long archive of unique global data will continue to be a resource well into the future. For example, the Indian Space Research Organization's (ISRO's) recently launched Ocean Satellite (Oceansat)-2, another Ku-band scatterometer similar to QuikSCAT. It is expected that the experience gained and the resources developed for QuikSCAT can be applied to facilitate the productive application of Oceansat-2 observations (Bourassa et al. 2010; see also http://www.ioccg. org/sensors/OCEANSAT_2.pdf).

Operational meteorological community interest in QuikSCAT grew gradually but steadily after the scatterometer became fully operational. It took time for methods to be developed that integrated the scatterometer data products into the mainstream National Weather Service forecast offices. In recent years, QuikSCAT has proven critical to improving marine warnings and hurricane forecasts. In fact, the National Centers for Environmental Prediction (NCEP) Ocean Prediction Center added a higher level of warning for ships ("hurricane force winds") for the midlatitude ocean based on the improved wind measurements from QuikSCAT (Sienkiewicz et al. 2006). The NCEP Tropical Prediction Center has also found QuikSCAT to be necessary for accurate hurricane forecasts and warnings (Chang and Jelenak 2008). A compendium of approximately 60 journal articles [from the American Geophysical Union (AGU) archives] presenting practical and scientific applications of QuikSCAT, and the previous scatterometer NSCAT, was published (AGU 2004; also available from T. Liu at w.t.liu@jpl. nasa.gov).

The loss of QuikSCAT has already had an impact on the operational meteorological community in the United Statets. Fortunately, the launch of Oceansat-2 by ISRO came just in time to provide continuity of $\mathrm{Ku}$ band scatterometer observations for climatological use. Unfortunately, the time needed to calibrate and validate the new instrument left a data gap for operational users.

In addition to the NSCAT/QuikSCAT/Oceansat-2 climate record for $\mathrm{Ku}$-band scatterometers, a long-term record of ocean winds from lower-frequency ( $\mathrm{C}$ band) scatterometers is also available. Including European Remote Sensing Satellite (ERS)-1, ERS-2, and Advanced Wind Scatterometer (ASCAT), the European Space Agency (ESA) has been obtaining ocean wind measurements since 1991 (Attema 1991; Figa-Saldana et al. 2002).

Full utilization of scatterometer winds is limited by the presence of rain, which affects about $7 \%$ of the global observations. Unfortunately, some of the most important and interesting meteorological events, such as storms, hurricanes, and El Niño-Southern Oscillation (ENSO), are accompanied by precipitation, so overcoming this limitation is a high priority. The effect of rain on the radar cross section measured by the scatterometer, and on the derived winds, depends primarily on the rain rate in the scatterometer footprint, the true surface wind speed, and the characteristics of the sensor (most importantly the signal frequency, polarization, and incidence angle of the microwave signal with the surface). Depending upon the combination of these factors, rain effects can range from negligibly small to large enough that the underlying wind signal is completely overwhelmed.

\section{Physical basis of scatterometry and rain interference}

The scientific and empirical basis for using microwave radar to infer sea surface winds was established in the 1960s. Empirical observations in wave tanks and from airborne field programs led to theoretical studies that associated Bragg scattering from wind-driven centimeterscale surface waves as the primary physical mechanism for the surface radar cross section variations (Plant 1986). Modulation of these capillary waves by the dominant gravity waves produces azimuthal variation in the radar cross section observed at steep incidence angles (Ulaby et al. 1986].

The potential for rain contamination of scatterometerderived winds has long been recognized (Wentz et al. 1982), but the magnitude of the impact has varied with 
instrument depending on the signal frequency and incidence angle of the microwave signal with the surface. The C-band (5 GHz) scatterometers, such as ERS-1 and -2 (Attema 1991) and ASCAT (Figa-Saldana et al. 2002) have smaller rain effects than Ku-band scatterometers, such as QuikSCAT (Fig. 1). In the 1990s we discovered that the lower incidence angle measurements from NSCAT demonstrated less rain effect than the higher incidence angle measurements. Figa and Stoffelen (2000) showed that for NSCAT's outer swath areas heavy rain has a clear (negative) impact on wind retrieval, and they consequently developed a quality control (QC) algorithm. The mixture of both high and low incidence angle measurements in NSCAT data meant that rain contamination was lower for NSCAT as compared to that in QuikSCAT, which has only two measurement beams, both at high incidence angles $\left(46^{\circ}\right.$ and $\left.54^{\circ}\right)$.

Rain affects the scatterometer-measured radar cross section signal in the following several ways:

1) Rain modifies the wind field through the downdrafts associated with the rain. This alters the surface wave spectrum. Smaller-scale downdrafts (as compared to scatterometer resolution) may produce subgrid variability, which in turn results in higher uncertainty in the scatterometer wind retrievals. However, as scatterometers move to higher resolution, they should be able to resolve downdraft effects.

2) Rain modifies the ocean surface (modulates the surface wave spectrum) by impinging on it (surface splash). At low wind speeds the most noticeable effect is that of surface roughening. In this regime the accepted rain impact model is for drops striking the water that create splash products (including rings, stalks, and crowns) from which the microwave signal scatters (Bliven et al. 1997). However, at high winds and rain, the rain may still have an effect because of a "rain-induced horizontal momentum transfer" (Le Mehaute and Khangaonkar 1990). This stress is based on the wind forcing of the raindrops, causing them to strike the surface at a steep angle from nadir, producing very different splash features. When this occurs, the nature of the roughness geometry and surface spectrum for short waves can be expected to be chaotic and dependent on the water wavelength. For example, raindrops impinging on the sea surface also generate turbulence in the upper water layer, which attenuates the short gravity wave spectrum ( $>10$-cm waves), while the centimeter-sized capillaries will get larger (Melsheimer et al. 2001). This could explain why rain may also modify the surface through wave-wave interactions, with the rain-induced capillary waves modifying the short gravity waves. The specific response of a particular sea surface may result in an increased normalized radar cross section (NRCS) at Ku band or a reduced NRCS at L band, depending on the existing wind speed and dominant surface spectrum. This is one reason why the effects of rain could be different for $\mathrm{C}$ band relative to $\mathrm{Ku}$ band. At storm-level wind magnitudes the sea spray and wave breaking further complicate the surface characteristics and air-sea interaction (Andreas 2004).

3) Rain modifies the propagation of the scatterometer signal through the atmosphere by attenuating the signal as it passes through the atmosphere in both directions; attenuation of the signal is most prominent at heavy rain rates $>5 \mathrm{~mm} \mathrm{~h}^{-1}$.

4) Rain modifies the propagation of the scatterometer signal through the atmosphere by increasing the signal that is scattered toward the instrument by adding the backscatter from the rain volume to that from the surface return.

In the last two points the volumetric effects of rain are significant for Ku-band, but less so for C-band instruments. While the first of these four effects might become a nonissue for future scatterometers with better spatial resolution, the remaining three effects will always adversely affect scatterometer wind retrievals, and their negative impact will be especially significant in the absence of independent observations of rain.

In most cases, the overall sum of the effect of rain is an increase in the measured radar cross section which, when not compensated for in wind retrieval, results in an increase in the retrieved wind speeds. An exception to this trend may be found in extremely high wind events, such as hurricanes, in which the attenuation effect of rain on the signal can dominate, leading to erroneously low retrieved winds. Rain contamination also results in erroneous turning of the retrieved wind directions toward a cross-track orientation (especially for Ku-band scatterometers). This erroneous cross-track wind direction retrieval results from the volumetric effects of the rain (attenuation and increased backscatter) because they mask the directional signal coming from the surface, confusing the retrieval into assuming that the wind is blowing cross track for which case there is no directional signal.

Figure 1 contains an example of the circumstance in which the QuikSCAT-measured NRCS and derived winds are higher because of the rain located throughout most of the storm. The estimated winds are relatively lower close to the eye for both QuikSCAT and ASCAT where the storm winds are highest, the rain is believed to be most intense, and the signal attenuation appears to be substantial. 

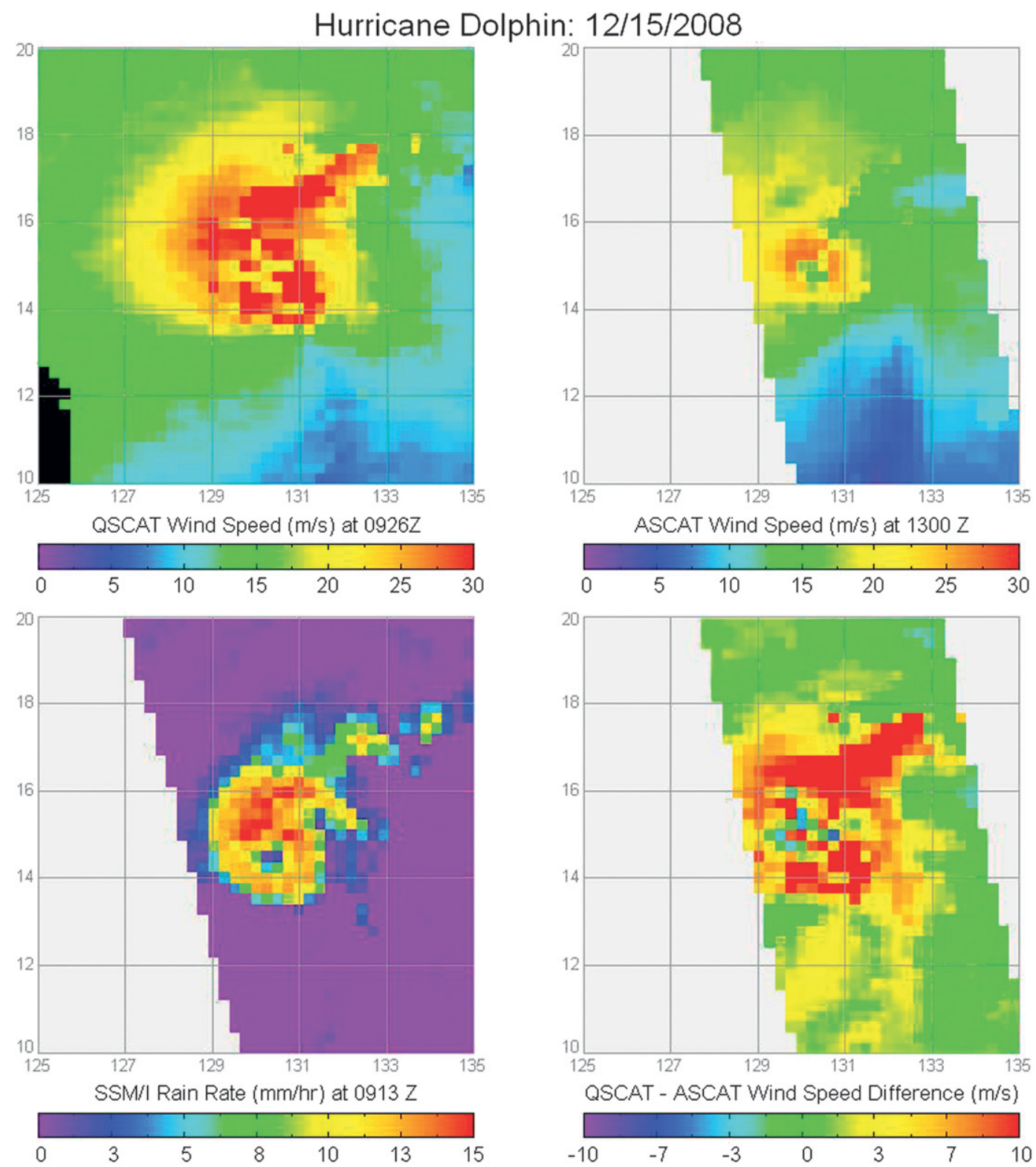

FIG. 1. Tropical Cyclone Dolphin observed by the (top left) Ku-band (13.4 GHz) QuikSCAT and the (top right) C-band (5.3 GHz) ASCAT scatterometers on 15 Dec 2008. (bottom left) Rain rate derived from SSM/I is also shown, along with (bottom right) the difference in wind speed between the scatterometer measurements. The higher-frequency Ku-band microwave signal suffers more rain effects than that of the $\mathrm{C}$ band. In this example, QuikSCAT and ASCAT data are shown for the storm. QuikSCAT-retrieved wind speeds are higher than the ASCAT winds away from the eye of the storm, and wherever rain is appreciable.

According to the Joint Typhoon Warning Center besttrack data, the maximum wind of Typhoon Dolphin was $46.3 \mathrm{~m} \mathrm{~s}^{-1}$ at 1200 UTC 15 December (JTWC reports 1-min mean winds; data can be found online at http://www. usno.navy.mil/NOOC/nmfc-ph/RSS/jtwc/best_tracks/). Conversion by conventional methods suggests a maximum sustained 10-min wind of approximately $38 \mathrm{~m} \mathrm{~s}^{-1}$. The storm was located at $15.1^{\circ} \mathrm{N}, 130.4^{\circ} \mathrm{E}$ at this time.
Future U.S. satellite scatterometer missions are planned to include both $\mathrm{Ku}$ - and C-band radar $(5.3 \mathrm{GHz})$ channels because $\mathrm{C}$ band is much less affected by rain than $\mathrm{Ku}$ band (see Table 1). The attenuation and volume scatter are markedly less at this frequency based on straightforward electromagnetic theory; however, the change in the surface splash backscatter is being investigated at this time using ASCAT and Next Generation Weather Radar 
TABLE 1. Previous and ongoing satellite scatterometer missions.

\begin{tabular}{|c|c|c|c|c|}
\hline Instrument and satellite & Dates in service & Spatial resolution & Scan characteristics & Operational frequency \\
\hline Seasat-A scatterometer & 7 Jul 1978-10 Oct 1978 & $50 \mathrm{~km}$ with $100-\mathrm{km}$ spacing & $\begin{array}{l}\text { Two sided } \\
\text { Double swath }\end{array}$ & $\mathrm{Ku}$ band $(14.6 \mathrm{GHz})$ \\
\hline$E R S-1$ scatterometer & Jul 1991-21 May 1997 & $50 \mathrm{~km}$ & $\begin{array}{l}\text { One sided } \\
\text { Single swath }\end{array}$ & $\mathrm{C}$ band $(5.3 \mathrm{GHz})$ \\
\hline$E R S-2$ scatterometer & 21 May 1997-present & $50 \mathrm{~km}$ & $\begin{array}{l}\text { One sided } \\
\text { Single swath }\end{array}$ & $\mathrm{C}$ band $(5.3 \mathrm{GHz})$ \\
\hline NSCAT & 15 Sep 1996-30 Jun 1997 & 25 and $50 \mathrm{~km}$ & $\begin{array}{l}\text { Two sided } \\
\text { Double swath }\end{array}$ & $\mathrm{Ku}$ band $(13.995 \mathrm{GHz})$ \\
\hline SeaWinds on QuikSCAT & 19 Jul 1999-23 Nov 2009 & 25 and $12.5 \mathrm{~km}$ & $\begin{array}{l}\text { Conical scan } \\
\text { One wide swath }\end{array}$ & Ku band (13.4 GHz) \\
\hline SeaWinds on $A D E O S-I I$ & Jan-Oct 2003 & 25 and $12.5 \mathrm{~km}$ & $\begin{array}{l}\text { Conical scan } \\
\text { One wide swath }\end{array}$ & $\mathrm{Ku}$ band $(13.4 \mathrm{GHz})$ \\
\hline ASCAT & Oct 2006-present & 50,25 , and $12.5 \mathrm{~km}$ & $\begin{array}{l}\text { Two sided } \\
\text { Double swath }\end{array}$ & $\mathrm{C}$ band $(5.255 \mathrm{GHz})$ \\
\hline Oceansat-2 & 23 Sep 2009-present & $25 \mathrm{~km}$ with $50-\mathrm{km}$ spacing & $\begin{array}{l}\text { Conical scan } \\
\text { One wide swath }\end{array}$ & $\mathrm{Ku}$ band $(13.5 \mathrm{GHz})$ \\
\hline
\end{tabular}

(NEXRAD) data (Weissman and Bourassa 2011). Much has been learned from studies based on the C-band ERS-1 and -2 scatterometers, and from ongoing studies using the recently launched Exploitation of Meteorological Satellites (EUMETSAT) ASCAT radar (Nie and Long 2007; Owen and Long 2010). In addition to the reduced rain contamination at $\mathrm{C}$ band, another reason for dualfrequency systems is that with both $\mathrm{Ku}$ - and $\mathrm{C}$-band frequencies available one can more readily estimate the extent of rain contamination, and those estimates can be used to correct the winds (Stiles et al. 2010).

The National Research Council (NRC) Committee on Earth Science and Applications from Space issued its decadal survey in 2007 and identified an Extended Ocean Vector Winds Mission (XOVWM) as a high national priority (National Research Council 2007) Its payload is planned to include a high-resolution dual-frequency scatterometer ( $\mathrm{Ku}$ and $\mathrm{C}$ bands) and a multifrequency radiometer to enable better rain detection and estimation. A nearer-term QuikSCAT follow-on project, featuring a straightforward QuikSCAT replacement, was proposed as a collaboration between NASA and the National Oceanic and Atmospheric Administration (NOAA; Gaston and Rodriguez 2008). These possible missions are awaiting budgetary authorizations. The recent satellites launched by India (ISRO's Oceansat-2 mission) and China (Haiyang $2 A$ ) carry only single-frequency, $\mathrm{Ku}-$ band scatterometers.

Part of the challenge in assessing rain effects in most observations is the disparity of scale size between the smaller homogeneous rain areas $(5-10 \mathrm{~km})$ of specific intensity versus the $30 \mathrm{~km} \times 40 \mathrm{~km}$ scatterometer footprint. An important issue for satellite wind sensors is the relative size and homogeneity of the rain areas with respect to each scatterometer measurement cell that collects a normalized radar cross section value, the socalled beamfilling effect, which refers to the partial coverage by rain inside the scatterometer's field of view (FOV). A typical wind vector estimate is derived using an algorithm that weights groups of NRCS measurements based on multiple azimuth looks of a given "spot" on the sea surface and two polarizations (for QuikSCAT). There is also more than one incidence angle. An illustration of the geometric variety of these observations is diagramed in Fig. 2.

There are three primary options for dealing with rain that is available to the producers of data for user applications and scientific investigations:

1) Detect the presence of rain and advise the users with a quantitative "flag" about the affected data, so that it

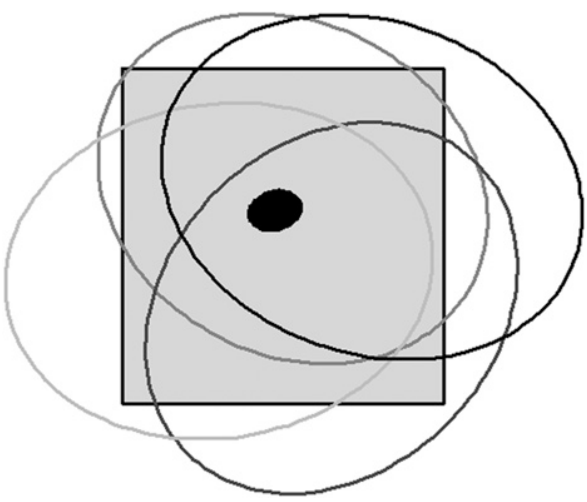

FIG. 2. Illustration of beam filling. A rain cell (black circular dot) is represented. The ellipses represent the areas (at the surface) of multiple scatterometer measurements that are combined to infer (or retrieve) the wind reported for the wind vector cell denoted by the square. 
can be ignored (discarded) or used with limited accuracy (Huddleston and Stiles 2000a,b; Mears et al. 1999).

2) Attempt to estimate the rain column parameters and incorporate them into a model that seeks to correct the NRCS for the attenuation, volume backscatter, and surface splash (Draper and Long 2004a; S. M. Hristova-Veleva et al. 2011, unpublished manuscript; Hristova-Veleva et al. 2006; Stiles et al. 2006; Hilburn et al. 2006; Weissman and Bourassa 2008; Nie and Long 2007; Owen and Long 2010).

3) Determine the wind speed empirically without any explicit attempt to estimate the rain parameters themselves, as is entertained in Stiles et al. (2010) and Stiles and Dunbar (2010). Instead, a simple neural network is used to determine a direct mapping from NRCS to wind speed in all weather conditions. This new concept is used in the Jet Propulsion Laboratory (JPL) reprocessing of QuikSCAT winds that became available to the validation team in August 2011 and should be available to the public shortly (contact B. W. Stiles for more information at bryan.w.stiles@jpl.nasa.gov). It is not described in detail here.

\section{Rain flagging}

Since rain contamination can degrade the wind measurement accuracy, vectors contaminated by rain need to be identified so that they can be treated properly during analysis. One approach is to "flag" measurements collected in rainy locations. Various rain flags have been developed and included in the scatterometer data files. A variety of different approaches to rain flagging have been employed (see the QuikSCAT rain flag summary, Table 2). Considerable QC development (including rain flagging) has been carried out in Europe as well [e.g., Stoffelen and Anderson (1997), ERS QC; Figa and Stoffelen (2000), NSCAT QC; Portabella and Stoffelen (2001), QuikSCAT QC; and Portabella and Stoffelen (2002)]. ASCAT has a quality flag that includes rain as one of their parameters. The ASCAT flag is therefore a type of goodness-of-fit flag (Portabella et al. 2011, manuscript submitted to IEEE Trans. Geosci. Remote Sens.).

\section{a. Use of collocated rain measurements}

Collocation of passive microwave radiometer data from a space-based platform is perhaps the most reliable method for detecting rain and flagging affected data. A radiometer-based rain flag requires a tight collocation of the time-space window in order to accurately identify rain effects (the best is $<30 \mathrm{~min}$, at $25 \mathrm{~km}$ ). Derived rain rates from Special Sensor Microwave Imager (SSM/I), Tropical Rainfall Measuring Mission (TRMM) Microwave Imager
(TMI), and Advanced Microwave Scanning Radiometer for Earth Observing System (EOS; AMSR-E) are included in the Remote Sensing Systems (RSS; http://www.remss. com) QuikSCAT data files for this purpose. However, the major disadvantage to this method is that the required tight time and space collocation window limits the amount of scatterometer data for analysis to roughly $30 \%$ of the QuikSCAT dataset. This is a strong disadvantage for a case study; however, when performing a statistical analysis, it may be less of an issue. Even so, even statistical studies can be impacted by the distribution of collocations. The fact that radiometer/scatterometer collocations often occur in specific geographical regions means that geographical variation in winds have to be considered to avoid biasing study conclusions. Note that the presence of rain does not necessarily indicate that the rain effects are strong enough to warrant flagging, especially at high wind speeds. This means that in addition to estimating the collocated rain rates, this technique also requires some understanding of how specific rain parameters affect the measured NRCS at a given wind speed. For example, at wind speeds less than $7 \mathrm{~m} \mathrm{~s}^{-1}$ moderate rainfall rates $(\approx 2$ $\mathrm{mm} \mathrm{h}^{-1}$ ) cause a surface splash effect that can change the NRCS appreciably [mainly for horizontal polarization (H-pol) for the $\mathrm{Ku}$ band (see Weissman and Bourassa 2008; Draper and Long 2004a)]. The effect is smaller at $\mathrm{C}$ band (Nie and Long 2007; Owen and Long 2010), but is still consequential.

\section{b. Autonomous and statistical methods}

Stand-alone rain flags based only on scatterometer data are another approach to rain flagging. Several standalone rain flags have been developed. The scatterometer project team at NASA's JPL has the responsibility for including information in their geophysical data products about the likelihood of rain effects. The wind vector products [level 2 B (L2B) files] include two statistical parameters that indicate the likely presence and the quantified impact of precipitation on the accuracy of each wind vector (Lungu 2006). The multidimensional histogram (MUDH) and empirically normalized objective function (ENOF) rain flags are two examples (see Table 2). The earliest version, the "nof_rain_index," was developed by a team at Remote Sensing Systems (Mears et al. 1999). It was derived using the ENOF rain-flagging technique produced by Remote Sensing Systems (see below). The objective function measures the difference between the observed radar return and that expected in the absence of rain (Mears et al. 1999). It is most useful for winds under $10 \mathrm{~m} \mathrm{~s}^{-1}$.

The MUDH rain flag is based on a multidimensional histogram. The histogram includes a number of rainsensitive parameters, such as beam difference, retrieved wind speed, retrieved wind direction, a normalized 


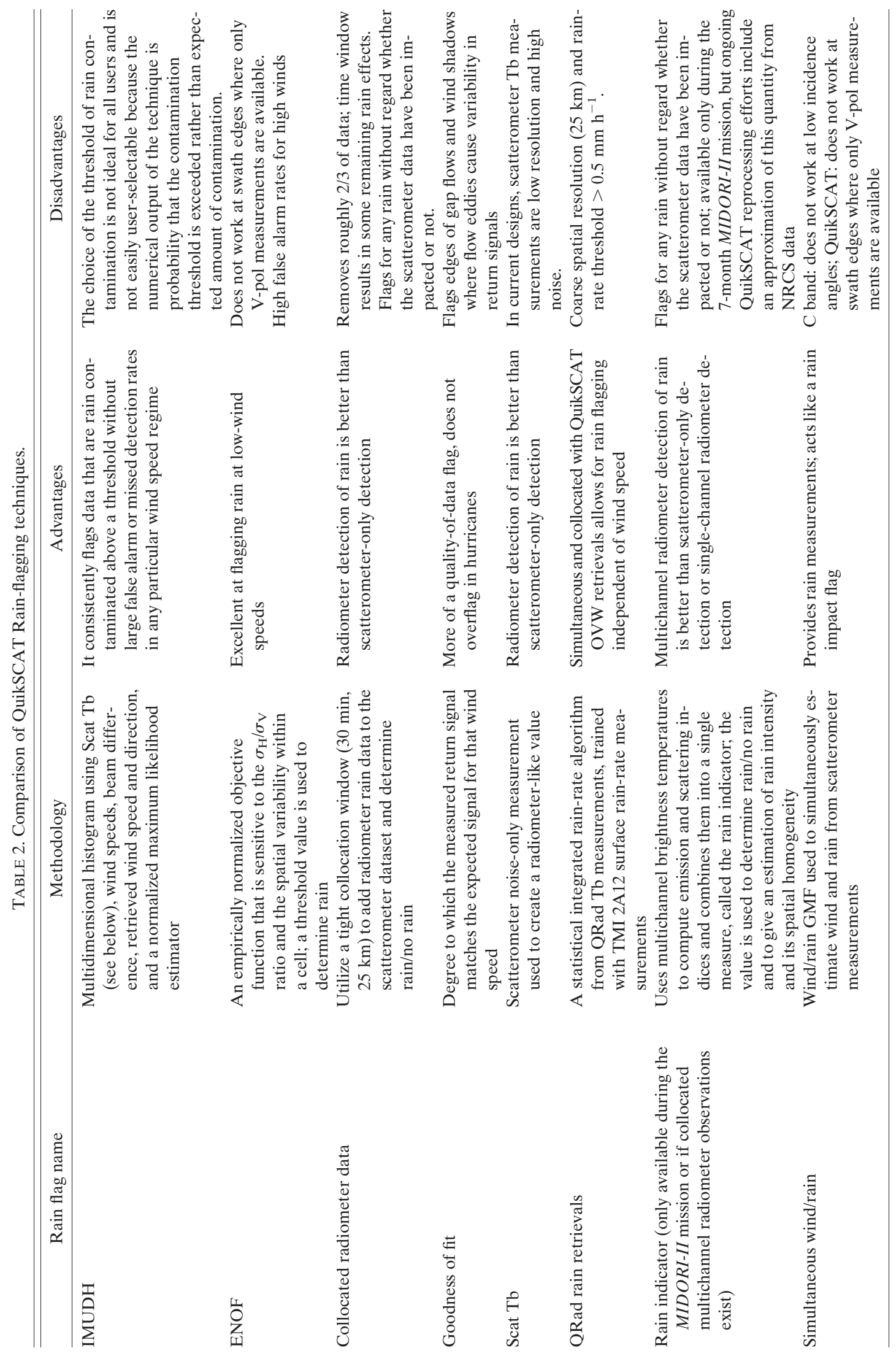


maximum likelihood estimator, and the scatterometer brightness temperature ( $\mathrm{Tb}$; Huddleston and Stiles 2000a,b). The current version of this flag in the JPL wind product is referred to as the impact multidimensional histogram (IMUDH). Like its predecessor MUDH, it operates autonomously on QuikSCAT data, but the algorithm was optimized and validated using the collocated AMSR data available in the Midori-II mission. The original MUDH algorithm was designed to discard any data with column-integrated rain rates over $2 \mathrm{~km} \mathrm{~mm} \mathrm{~h}^{-1}$. IMUDH only discards data in which the rain is sufficient to contribute more than $2 \mathrm{~m} \mathrm{~s}^{-1}$ or $30^{\circ}$ of error to the retrieved wind speed and direction, respectively. The original MUDH algorithm was validated by comparison with $\mathrm{SSM} / \mathrm{I}$ rain rates. The IMUDH algorithm was validated by comparison to estimates of wind error resulting from rain derived from SeaWinds and AMSR collocations. The algorithm constituting this method works equally well for both the SeaWinds and QuikSCAT datasets. As depicted in Fig. 3, IMUDH alleviates the problem of overflagging high wind speeds regions that plagued MUDH. For similar rain rates, high winds are less impacted by rain than lower winds. Because IMUDH is impact based, it flags fewer high winds as being rain contaminated.

The simple radiometric Tb used in IMUDH is determined from the instrument noise measurement used in sigma-0 determination. This procedure converts the hardware used for noise measurement to a radiometer, albeit an imprecise one. The radiometer, thus produced, is referred to as QRad. In addition to its brightness temperature measurement, a QRad rain retrieval algorithm (Ahmad et al. 2006) has been implemented in the JPL L2B data product to infer instantaneous and collocated oceanintegrated rain-rate measurements with wind retrievals. This statistical algorithm was trained using near-simultaneous Tb observations by QRad and the TMI 2 A12 surface rain rates (Ahmad et al. 2005). Typical results shown below in Fig. 4 demonstrate that QRad rain-rate measurements are in good agreement with TMI microwave rain observations.

\section{c. Multiparameter-based methods}

Remote Sensing Systems developed several methods of rain detection for QuikSCAT and a correction scheme for SeaWinds based on the use of collocated radiometer data. The correction scheme is described in section 5a. The two rain flags are ENOF and a goodness-of-fit flag. The ENOF rain flag is based on an empirically normalized objective function. The objective function measures the difference between the observed radar return and that expected in the absence of rain (Mears et al. 1999). This rain flag is provided in the JPL Physical Oceanography Distributed Active Archive Center (PO.DAAC)

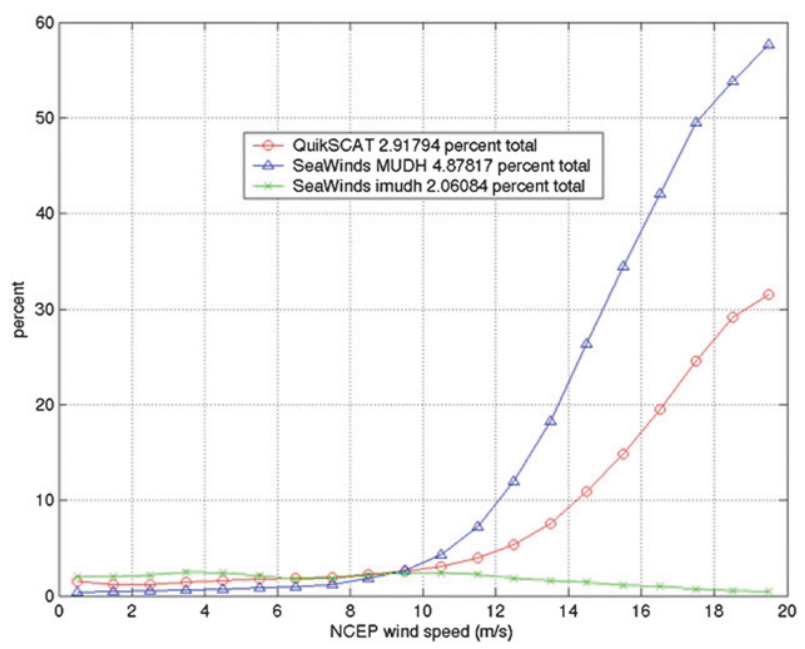

FIG. 3. Percent of rain-free wind vector cells flagged for rain vs NCEP wind speed. Cells were determined to be rain free if SSM/I collocations within $30 \mathrm{~min}$ and $25 \mathrm{~km}$ had identically zero rain rates. QuikSCAT MUDH (red curve) is shown, as is a very early version of MUDH for SeaWinds on Midori-II (blue curve) and an early version of IMUDH (green curve).

QuikSCAT L2B product. In addition, another rain flag was produced by RSS that functions more as a quality flag than a rain flag, but serves the purpose of removing rainaffected data. Winds in the presence of rain, but not strongly affected by the rain (such as high winds in tropical cyclones), are not flagged. This second rain flag is included in the RSS QuikSCAT binary gridded files. Collocated radiometer rain rates are included in these files when data are available within a 30-min time window, which limits its availability to only about one-third of the QuikSCAT data.

The flagging of rain-contaminated data can be problematic because one often has to choose between flagging large amounts of good data or leaving significant amounts of contaminated data unflagged (Huddleston and Stiles 2000b). Wind vectors around storms are important for global vorticity analysis, and these are often accompanied by rainfall. Unfortunately, flagging all rainy areas as contaminated often removes from the analysis the most dynamic and interesting portions of the wind field. An alternative to merely discarding rainflagged data is to correct for the effects of rain on the measurements. This is considered in the following sections. If effective corrections to the wind observations are not possible, such observations need to be identified and properly treated in later analysis.

\section{Rain correction (simultaneous wind and rain retrieval) using the scatterometer alone}

Because the greatest rain effects occur in tropical regions and along midlatitude fronts, which are regions of 

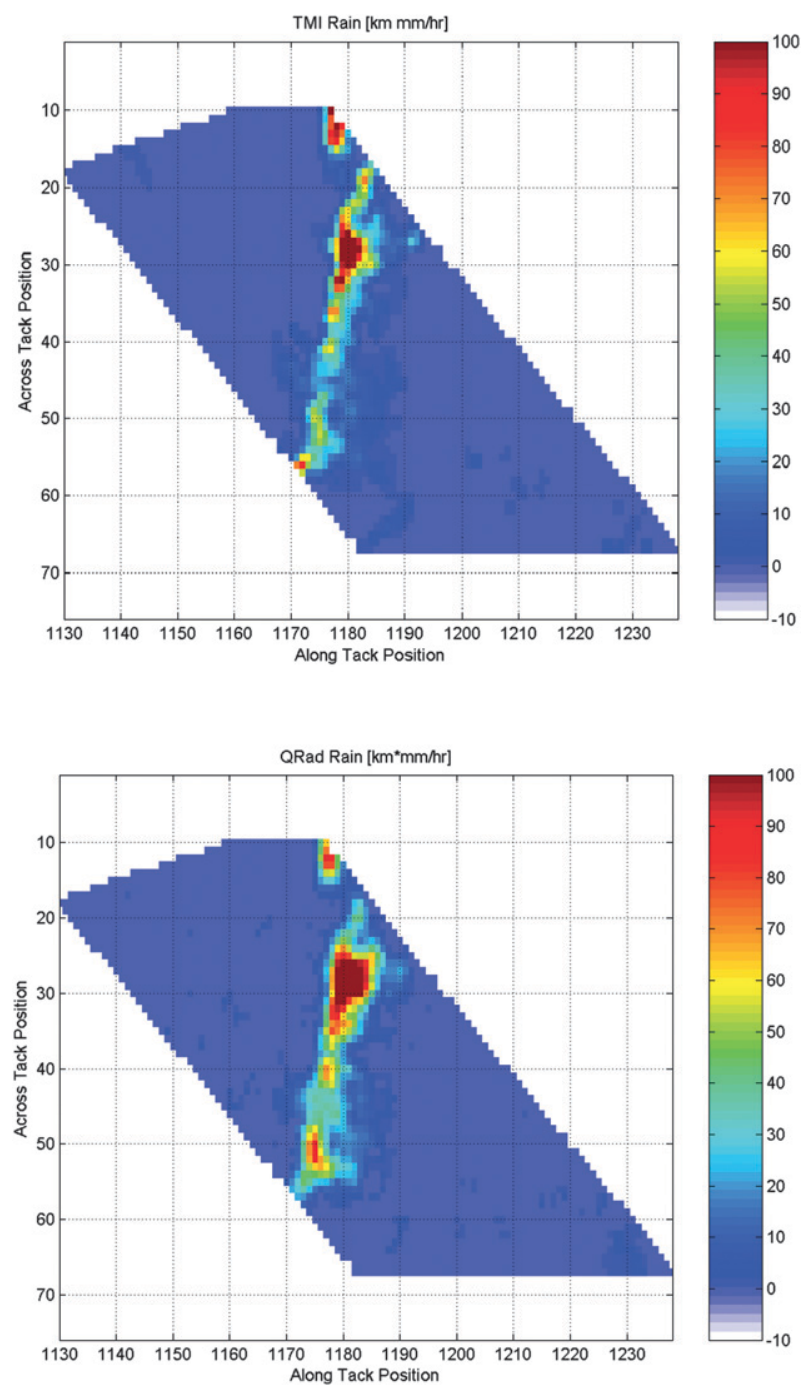

FIG. 4. A typical example of rain event found in the (top) TMI 2A12 product and (bottom) QRad product. Spatial resolution is $25 \mathrm{~km}$ (WVC grid) and coincidence time difference is approximately $10 \mathrm{~min}$.

great interest, there is a need to correct for the effects of rain in order to increase the number of data available for analysis in dynamically important regions. With some limitations a simultaneous wind and rain retrieval technique that uses only scatterometer data can be used. Alternately, data from other sensors can be employed. In this section we consider rain mitigation using only scatterometer data and consider other sensor data in the next section.

The Microwave Earth Remote Sensing (MERS) Laboratory at Brigham Young University (BYU) has engaged in several areas of investigation and developed numerous techniques for addressing the rain issue for QuikSCAT and other satellite sensors (e.g., Draper and
Long 2004b; Nie and Long 2008; Nielsen and Long 2009; Owen and Long 2011a). Of particular interest are the methods based only on scatterometer observations. Simultaneous wind and rain (SWR) estimation has been proposed as a method for 1) detecting the presence of rain, 2) determining whether the rain effect is significant enough to contaminate the wind retrieval, 3) correcting (where possible) the rain-contaminated backscatter measurements to enable accurate wind retrieval, and 4) estimating the rain rate, and thereby providing additional information from the measurements. SWR retrieval is a scatterometer data-only method that is based on extending the scatterometer wind geophysical model function to include rain to produce a combined wind-rain geophysical model function. In formulating the wind-rain geophysical model function the rain backscatter model is (often) simplified into a rain attenuation term and a net effective backscatter term, which incorporates both the effects of backscatter from falling rain and the adjusted backscatter of the rain-modified surface (Draper and Long 2004a). At $\mathrm{C}$ band the latter term is almost exclusively due to surface modification (Nie and Long 2007; Weissman and Bourassa 2011), while both falling rain and surface modification can be important at Ku band (Draper and Long 2004b; Owen and Long 2011a).

In the combined wind-rain model function the scatterometer-measured backscatter is modeled as

$$
\sigma_{M}^{0}=\left(\sigma_{w}^{0}+\sigma_{\mathrm{sr}}^{0}\right) \alpha+\sigma_{r}^{0},
$$

where $\sigma_{M}^{0}$ is the measured backscatter; $\sigma_{w}^{0}$ is the windinduced surface backscatter, assumed to be the same as the conventional rain-free model function; $\sigma_{\mathrm{sr}}^{0}$ is the surface backscatter perturbation resulting from impinging rain; $\alpha$ is the attenuation of the scatterometer signal resulting from rain; and $\sigma_{r}^{0}$ is the backscatter resulting from the falling rain. For simplicity, this model is often expressed as

$$
\sigma_{M}^{0}=\sigma_{w}^{0}(u, \theta) \alpha(R)+\sigma_{\text {eff }}^{0}(R),
$$

where $\sigma_{\text {eff }}^{0}$ is the effective backscatter resulting from rain for a rain rate of $R$. Note that the wind speed $u$ and direction $\theta$-dependent component of the geophysical model function are treated as being independent of the rain. Using either the TRMM precipitation radar (PR) backscatter and rain-rate estimates or the AMSR attenuation and rain measurements, parameters of a logquadratic expression of rain rate and attenuation versus rain rate are estimated (Draper and Long 2004b; Nie and Long 2007; Nielsen and Long 2009; Owen and Long 2011a). Figure 5 shows a plot of the Ku-band geophysical wind and rain model function. Note the sinusoidal 

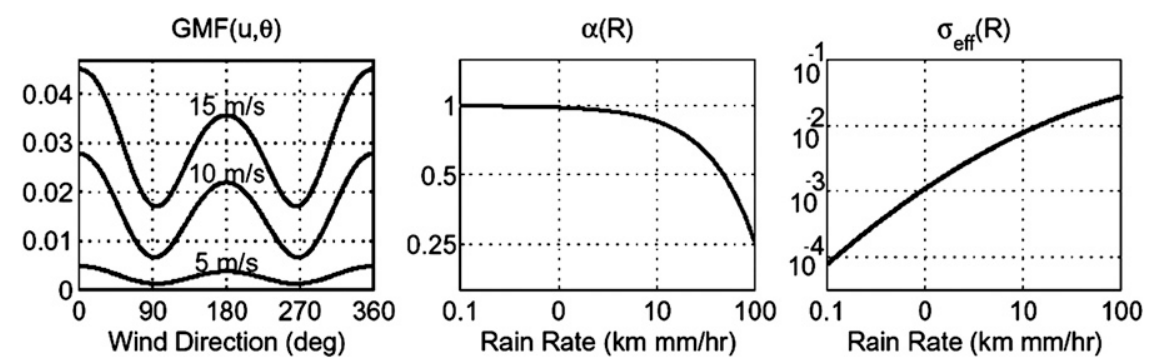

FIG. 5. Ku-band simultaneous wind/rain geophysical model function (Draper and Long 2004a).

variation of $\sigma_{M}^{0}$ with wind direction, which leads to multiple directional ambiguities in the estimated wind and necessitates an ambiguity selection algorithm. As suggested by Eq. (2), rain attenuates the signal, with attenuation increasing with rain rate. As long as the attenuation is not too large, the azimuth variation in the wind-induced backscatter can still be detected, enabling estimation of the wind direction. The rain attenuation reduces the apparent wind speed, but this is offset to a degree by the increased backscatter from the rain. The latter is not, however, a function of the wind direction. Thus, the rain and wind signatures in the backscatter can be separated by combining multiple backscatter measurements at different azimuth directions.

For vector wind retrieval, multiple backscatter measurements taken at different azimuth angles are combined using maximum likelihood (ML) techniques to estimate the wind and rain. In SWR retrieval, the conventional wind-only ML objective function is modified to incorporate the rain-rate estimate and the wind-rain geophysical model function. (Draper and Long 2004b; Nie and Long 2008). When excessive rain attenuation is encountered, the wind cannot be retrieved, though rain rate can still be estimated (Allen and Long 2005; Owen and Long 2011b). Combining SWR with reconstruction/resolution enhancement techniques can ameliorate rain cell beam-filling issues because the wind and rain are retrieved at scales approaching the size of rain cells (Owen and Long 2011a,b). Because it requires no other data, the SWR is applicable over the full QuikSCAT and SeaWinds missions.

\section{Rain correction combining scatterometer and other sensor measurements}

Another approach to rain mitigation is based on the use of independent observations collected from other sensors, typically microwave radiometer data, though ground-based radar can also be used. An effective method, the key limitation of this approach is that it can be used only when collocated radiometer or groundbased radar is available.

\section{a. Using AMSR microwave radiometer data}

The combination of the SeaWinds scatterometer and AMSR radiometer on the Midori-II satellite made it possible to develop rain correction algorithms for scatterometer data, which can either minimize or remove the effect of rain on the scatterometer winds. Described below are several alternative approaches that have been developed. These rain corrections can also be applied to QuikSCAT data, but only when collocated data from a microwave radiometer is available because the radiometer measurements are necessary for rain correction. For example, such corrections can be used whenever AMSR-E is collocated with QuikSCAT. Although these techniques were specifically developed for AMSR, similar techniques could probably be applied to collocations of one of the SSM/I radiometers and QuikSCAT.

\section{1) RSS APPROACH}

Hilburn et al. (2006) developed the rain correction using AMSR brightness temperatures to correct SeaWinds radar cross sections, which could then be used to retrieve wind speeds and directions. The correction was physically based on modeling attenuation, backscatter, and rain roughening of the surface; and the coefficients of the correction were empirically determined using NCEP Global Data Assimilation System (GDAS) winds. The work highlighted the importance of the rain-roughening term, especially at low rain rates where rain backscatter alone cannot explain the magnitude of the rain effects. The work also showed how accounting for nonuniform beamfilling (when the quantities that affect the NRCS vary appreciably within the area illuminated by the antenna beam) is important for estimating the attenuation of the scatterometer signal. Finally, the work showed how variability in the relationship between rain rate and rain backscatter complicate the removal of rain contamination. Substantial improvements in wind speed with more modest improvements in wind direction were found, particularly in the overall statistical characteristics of the dataset (Fig. 6). 


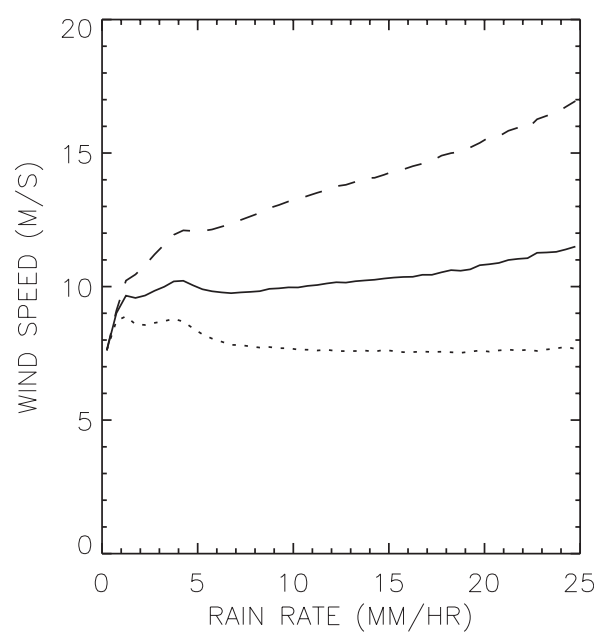

FIG. 6. RSS SeaWinds globally averaged wind retrievals for uncorrected data (dashed), rain-corrected data (solid), and NCEP wind speeds (dotted), which are plotted vs AMSR rain rates. Note that while improved, the correction does not remove all of the rain effect relative to NCEP winds.

\section{2) JPL APPROACH}

The scatterometer project team at NASA's Jet Propulsion Laboratory used the AMSR and scatterometer measurements as inputs to a three-step rain correction strategy (S. M. Hristova-Veleva et al. 2011, unpublished manuscript; Hristova-Veleva et al. 2006; Stiles et al. 2006). First, they retrieved rain, atmospheric, and surface quantities from the AMSR multiple frequency channels of brightness temperatures. Next, they developed two complementary methods (physical and empirical) to quantify the impact of rain on scatterometer measurements as a function of the retrieved geophysical parameters. Finally, they corrected the scatterometer measurements using each of the two rain impact models and retrieved new wind fields from the corrected measurements.

Both of their rain correction methods (physical and empirical) are improvements over the standard wind retrieval. As mentioned already, the presence of rain in the scatterometer FOV often results in the retrieval of winds that are erroneously oriented in a cross-track direction ( at $\sim 90^{\circ}$ and $\sim 270^{\circ}$ ) and have higher speeds than both the buoy and global model winds suggest. The details of each of the three steps are described below and a performance comparison is provided.

\section{3) RAIN RETRIEVALS}

S. M. Hristova-Veleva et al. (2011, unpublished manuscript) developed a passive microwave rain retrieval algorithm that uses AMSR brightness temperatures to estimate the rain and other atmospheric and surface parameters inside the scatterometer FOV. Their passive microwave rain retrieval algorithm addresses the issues of nonuniform beam filling and hydrometeor uncertainty, thus aiming to resolve some of the outstanding problems associated with cloud and precipitation retrievals identified by Stephens and Kummerow (2007). In addition to rain estimates, the algorithm retrieves a number of parameters describing the atmosphere and the underlying surface [sea surface temperature (SST), vertically integrated water vapor $(V)$, vertically integrated total liquid ( $L$; the columnar cloud water plus rainwater), and rain rate]. Simultaneous retrieval of all these parameters reduces geophysical cross talk and leads to more accurate estimates of the rain (particularly, light rain).

4) Estimating THE RAIN-INDUCED MODIFICATIONS OF THE SCATTEROMETER MEASUREMENTS

\section{(i) Rain corrections: Physical approach}

Estimation of the near-surface wind velocity from scatterometer measurements is based on the assumption that variations in the measured power are due to variations in the normalized radar cross section $\left(\sigma^{0}\right)$ of the ocean surface that result solely from variations in the wind. Hence, correcting the scatterometer wind for rain requires correcting the $\sigma^{0}$ measurements for the rain-induced effects. This requires accurate estimates of not only the vertically integrated precipitation amounts but also of the surface rain rate. As already described in section 2 , the scatterometer signal is impacted in three ways: the signal is attenuated by the rain, clouds, and vapor in the atmosphere; the signal is augmented by the backscatter from rain droplets in the atmosphere; and, finally, the signal is augmented by the roughening of the ocean surface that is induced by the rain rate at the surface (the "splash" components, whose properties are affected by rain and wind). The relative effects of these processes will depend on the wind and rain magnitudes.

The physical approach employed by Hristova-Veleva et al. (2006) estimates the three rain effects separately using parameterized relationships between retrieved geophysical parameters (total liquid water and rain rate) and the scatterometer effects (volume attenuation, volume rain backscatter, and rain-induced surface roughening). As such, the approach uses statistical relationships (e.g., $Z=a R^{b}$ ) that reflect drop size distribution (DSD) dependence, etc. We refer to it as "physical" because numerical wind products were not explicitly used to regress the model parameters.

In particular, while developing the AMSR geophysical retrieval algorithms S. M. Hristova-Veleva et al. (2011, unpublished manuscript) used a radiative transfer model to compute the radiometric signatures (attenuation and 
brightness temperatures) that are associated with the hydrometeor profiles in the retrieval databases. The radar reflectivity at $13.4 \mathrm{GHz}$ can be easily computed once the rain rate has been determined and the DSD assumptions have been made. The radar reflectivity is then used to compute the volumetric precipitation backscatter. In this process, the attenuation of the intervening layers is also accounted. Finally, the rain-induced surface roughening (the "splash" effect) is computed as function of the rain rate following results from observational studies (Stiles and Yueh 2002; Contreras et al. 2003).

The rain correction proceeds by solving for $\sigma_{w}^{0}$ from Eq. (1) using the estimated by the above method attenuation $(\alpha)$, volume rain backscatter $\left(\sigma_{r}^{0}\right)$, and surface $\operatorname{splash}\left(\sigma_{\mathrm{sr}}^{0}\right)$.

\section{(ii) Rain corrections: Empirical approach}

The empirical method (Stiles et al. 2006) compares the observed $\sigma_{\text {SeaWinds }}^{0}$ to the NCEP model wind-inferred $\sigma_{\text {NCEP }}^{0}$ to estimate the rain corrections as function of the AMSR-derived geophysical parameters [Eq. (3)]:

$$
\begin{aligned}
\sigma^{0}(\text { SeaWinds })= & A(L, V, \mathrm{SST}) \sigma^{0}(\mathrm{NCEP}) \\
& +B(L, V, \mathrm{SST})
\end{aligned}
$$

NCEP winds are employed to estimate equivalent rainfree backscatter values. The rain-induced attenuation $A$ and additive backscatter $B$ components are then regressed as a function of SST, vertically integrated vapor $(V)$, liquid $(L)$, and antenna beam. NCEP winds are only used in regressing the parametric model. The empirical approach estimates attenuation and effective backscatter that combines the rain volume backscatter and the attenuated rain-induced surface effects [the splash resulting from rainfall and rain-wind interaction (Weissman and Bourassa 2008)].

The $A$ and $B$ values are obtained by empirical fitting in a two-step process. The first step chooses the $A$ and $B$ that minimize the mean-square difference between the right and left sides of Eq. (3). The second step normalizes $A$ and $B$ so that $B$ is zero and $A$ equals the physically derived attenuation when $L<0.2 \mathrm{~mm}$. This prevents biases resulting from NCEP from contaminating the corrected scatterometer (SeaWinds) winds. The rain correction proceeds by subtracting $B$ from the sigma0 measurements and then dividing by $A$. The NCEP winds are only used to fit $A$ and $B$ as a function of $L, V$, and SST; they are not used when the correction is applied.

The physical and empirical models have complementary advantages and disadvantages. The physical model is limited because several important components of the rain impact are not well understood, including surface roughening resulting from rain (splash and propagating ring waves) and polarization-dependent differences in backscatter from the rain column. The empirical model, because it is regressed from the data, compensates for the poorly understood physics, but it has the disadvantage that systematic errors in the numerical wind product can creep into the model. The functional form of the empirical model has been chosen to reduce the impact of such errors, but it is impossible to remove them entirely. Furthermore, the empirical approach produces estimates of the average conditions and, currently, cannot account entirely for the partial beam filling by the rain.

\section{(iii) Results}

Applying the AMSR-based physical and empirical atmospheric correction to the scatterometer observations has resulted in significant improvement of the scatterometer winds in rainy conditions. The entire Midori-II mission 7-month dataset was used to evaluate these methods. Figure 7 shows the distributions of the uncorrected scatterometer winds (in black) and compares them to the distributions from two global models (two shades of green) and the two versions of AMSR-corrected winds [in red for the physical correction (Hristova-Veleva et al. 2006) and cyan for empirical (Stiles et al. 2006)]. The effect of the rain contamination on the uncorrected scatterometer winds is illustrated by how the black curve deviates from the two green curves as the amount of the rain increases inside the satellite's FOV (from top to bottom). The two most important contributions of the corrections are the removal of speed biases as a function of rain rate and the reduction of the rain-induced cross-swath directional preference.

\section{b. QRad-based methods}

Another rain correction approach to measuring ocean wind vector is the active/passive Q-Winds retrieval algorithm (Laupattarakasem et al. 2010). The algorithm has been applied with modest success to measuring tropical cyclones, which are usually associated with high wind speeds and strong rainbands. It combines simultaneous QRad $\mathrm{Tb}$ with the conventional multiazimuth radar-look ocean backscatter measurements to retrieve ocean wind vectors in the presence of rain for extreme wind events. The algorithm was trained using 25 QuikSCAT hurricane overpasses from 2001 to 2008, collocated with the NOAA Hurricane Research Division (HRD) $\mathrm{H}^{*}$ Wind surface wind analyses.

Although the Q-Winds algorithm utilizes a maximum likelihood estimation (MLE) wind vector retrieval technique similar to that of QuikSCAT L2B-12.5 km, there are some notable differences. First, Q-Winds uses both active $\sigma^{0}$ and passive horizontal polarized brightness temperature $(\mathrm{TbH})$ measurements to infer 

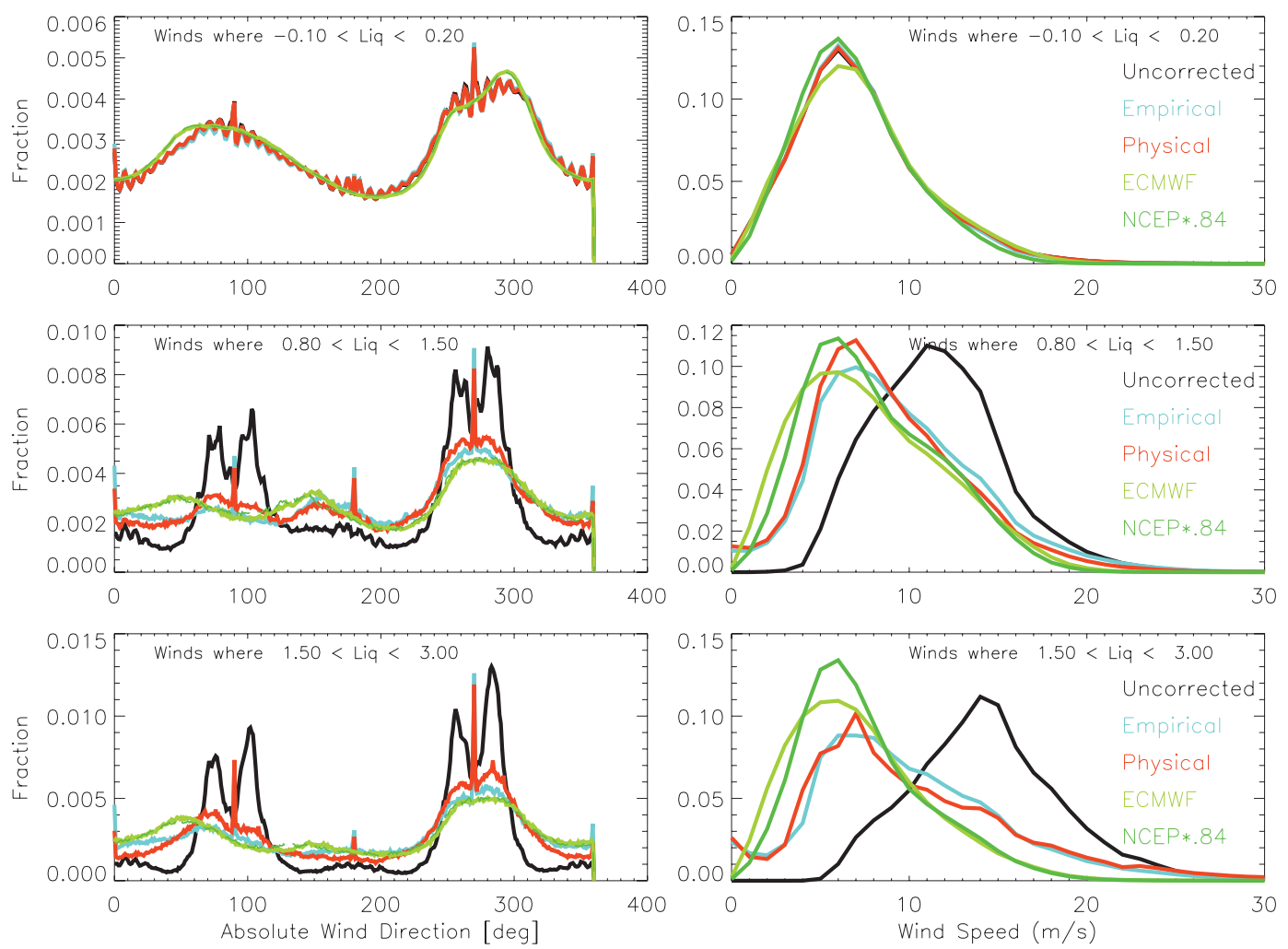

FIG. 7. Distribution of (left) wind direction and (right) speed for three different categories of retrieved total liquid: (top) nonrainy areas, (middle) medium-intensity rain, and (bottom) high-intensity rain. Shown are five different fields: ECMWF and NCEP model fields (two shades of green), uncorrected scatterometer winds (black), and two different corrections based on the AMSR retrievals [red (the physical correction) and cyan (the empirical correction)] are shown.

ocean surface wind vector in the presence of rain. This is accomplished using a special "extreme winds" geophysical model function (XW-GMF), which models the effects on $\sigma^{0}$ of both rain and surface winds, as shown in Fig. 8. In this GMF development, rain effects were implicitly modeled by sorting QuikSCAT $\sigma^{0}$ observations by $\mathrm{H}$-pol brightness temperatures, which were highly correlated with the average precipitation environment.

Second, Q-Winds uses the QRad $\mathrm{TbH}$ to produce an excess rain quality assurance flag, which is significantly different from the L2B-12.5 km MUDH rain flag. In the L2B-12.5 km ocean vector winds (OVW) product, the multidimensional histogram rain probability $>0.1$ is recommended as rain flag threshold; however, this value causes the majority of high wind speed retrievals to be flagged as rain. Thus, for hurricane conditions, this MUDH probability level has difficulty in discriminating rain-degraded retrievals from valid high wind speed solutions. On the other hand, the Q-Winds excess rain flag (QERF) algorithm uses a simple threshold for QRad TbH, which is based upon Q-Winds retrieval errors from the QuikSCAT hurricane training set.
Figure 9 shows a comparison between the MUDH and Q-Winds rain flagging for Hurricane Fabian.

An example of Q-Winds retrievals in Hurricane Fabian (September 2003) and L2B-12.5 km wind vectors compared with the $\mathrm{H}^{*}$ Wind surface truth is presented in Fig. 10. Each subpanel is a hurricane surface wind image in a $5^{\circ} \times 5^{\circ}$ analysis window with the hurricane eye (based upon the National Hurricane Center's best-track location) centered at coordinates $(20,20)$, and the $y$ and $x$ coordinates are latitude and longitude, respectively, on a relative scale of $0.25^{\circ}(25 \mathrm{~km})$ increments. In each panel, wind speeds are presented in the same color scale that ranges from 0 to $50 \mathrm{~m} \mathrm{~s}^{-1}$, and the arrows are the decimated flow directions.

Statistically, the overall wind speed retrieval performance of Q-Winds and L2B-12.5 km is assessed using the composite of 10 independent hurricane revolutions, and results are shown in Fig. 11. The upper panel is the binned average wind speed comparison before applying rain flags, and the lower panel is after the rain flags are applied. These comparisons with $\mathrm{H}^{*}$ Wind speeds demonstrate that Q-Winds retrievals (solid blue lines) are 

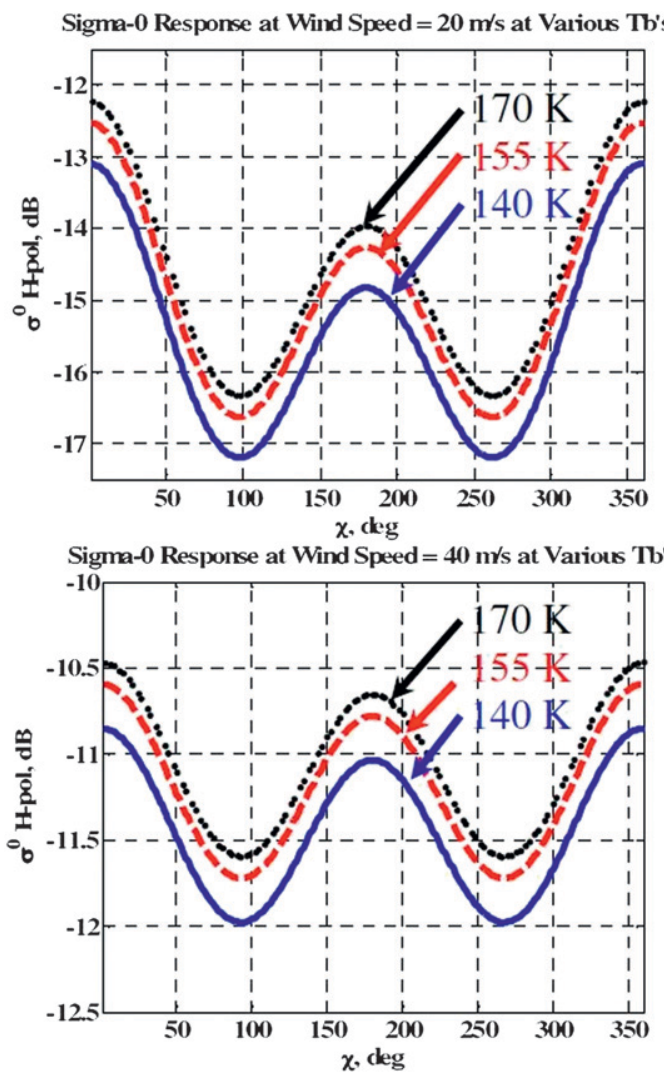

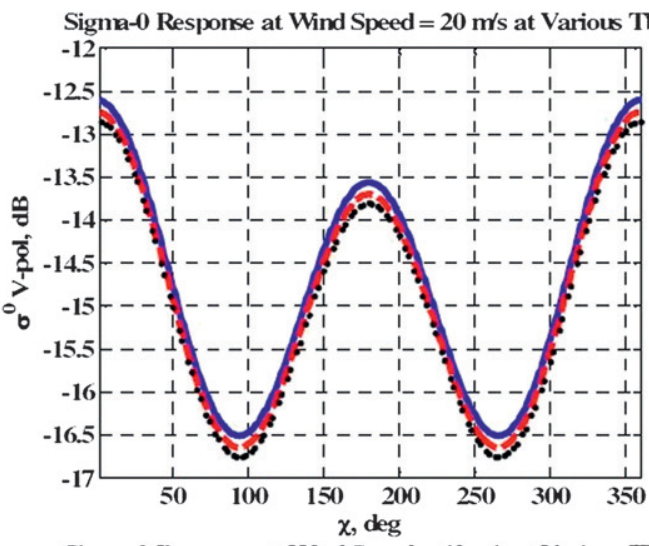

Signa-0 Response at Wind Speed $=\mathbf{4 0} \mathrm{m} / \mathrm{s}$ at Various Tb's

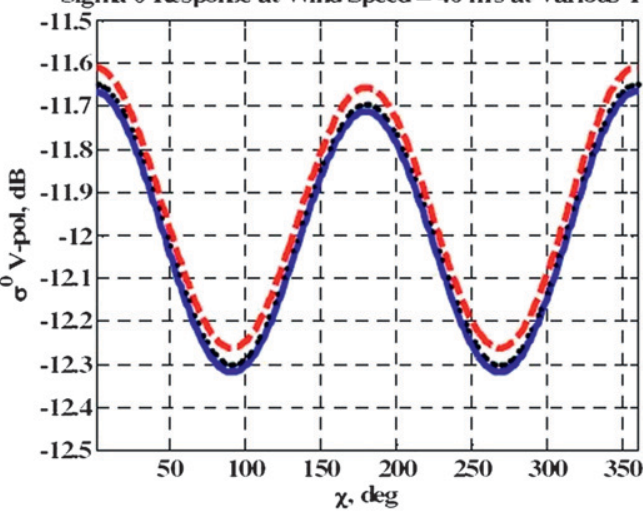

FIG. 8. Example of XW-GMF for wind speeds of (top) 20 and (bottom) $40 \mathrm{~m} \mathrm{~s}^{-1}$ for (left) H-pol and (right) V-pol. The effects of precipitation are most pronounced for $\mathrm{H}$-pol $\sigma^{0}$ by changes in the mean for $\sigma^{0}$ curves for increasing values of TbH (blue: 140, red: 155, and black: $170 \mathrm{~K}$ ), which corresponds to greater intensity rain.

superior to L2B-12.5 $\mathrm{km}$ retrievals (dashed red lines) for both cases (both with and without rain flags applied). This is especially evident in the right panel, where after the quality rain flags have been applied; the Q-Winds are in good agreement in the mean for wind speeds greater than $40 \mathrm{~m} \mathrm{~s}^{-1}$. However, because high wind speeds are usually associated with strong rain, the resulting wind speed comparison standard deviations are high because of the imperfect rain correction of QRad Tbs.
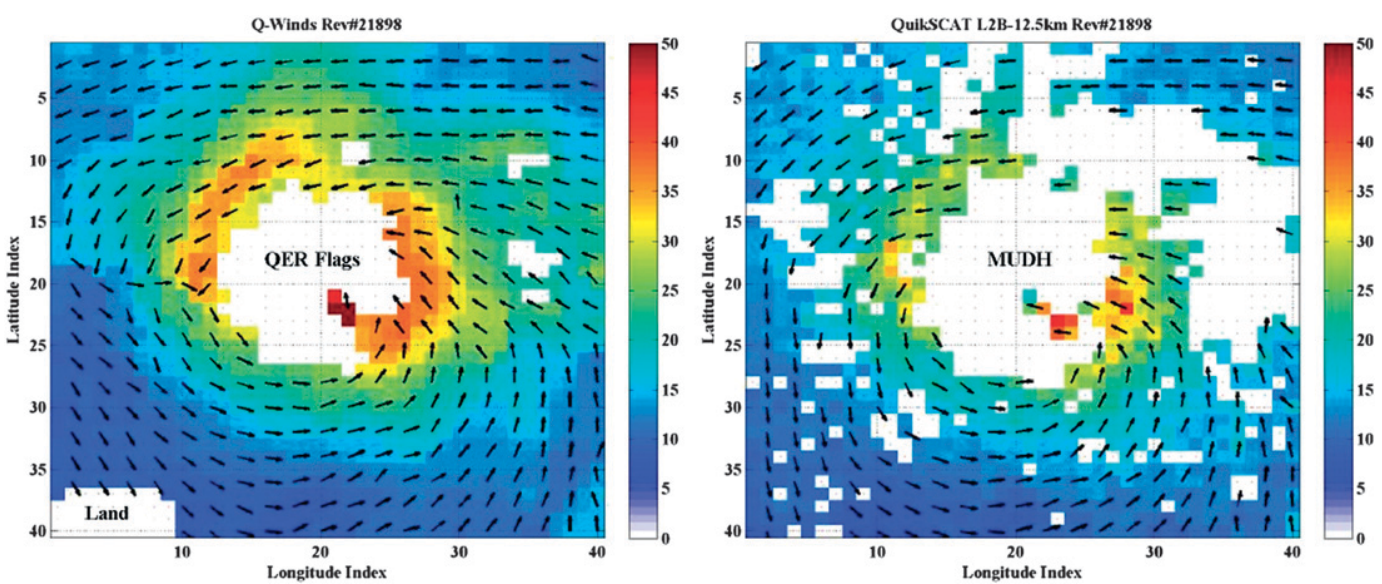

FIG. 9. Q-Winds and L2B-12.5 km-retrieved OVW images with quality rain flags applied for Hurricane Fabian: (left) Q-Winds and (right) L2B-12.5 km. 

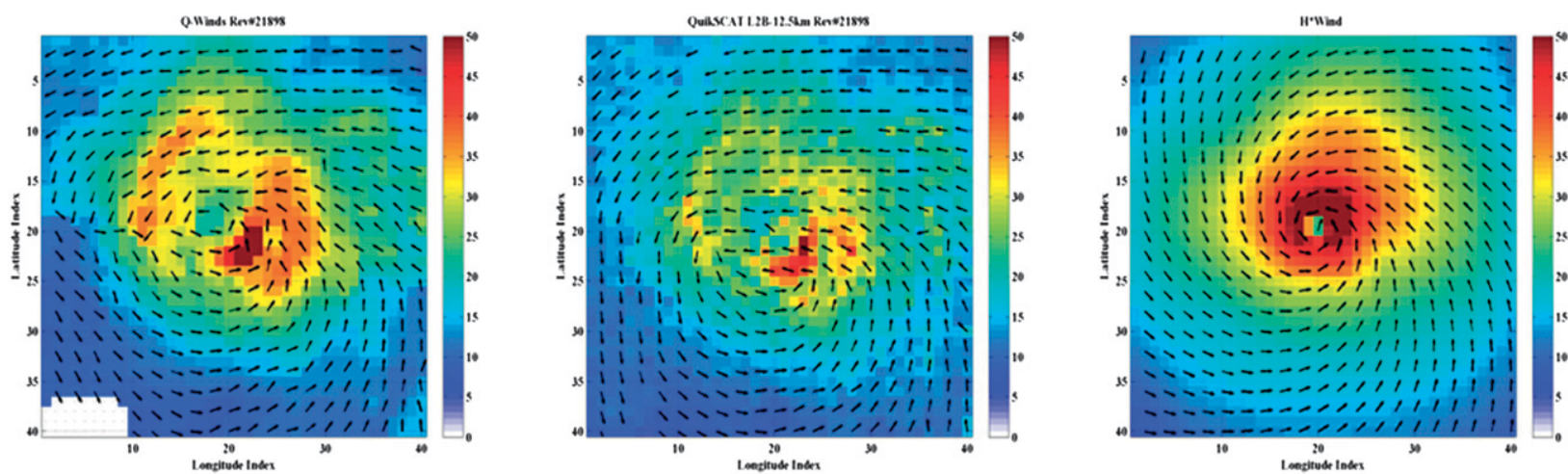

FIG. 10. Hurricane Fabian (2003) surface wind field: (left) Q-Winds retrievals, (middle) JPL L2B-12.5 km, and (right) NOAA HRD $\mathrm{H}^{*}$ Wind surface analysis.

Finally, Q-Winds and L2B-12.5 km wind direction retrieval performance was assessed by comparing with $\mathrm{H}^{*}$ Wind directions for the same composite of 10 validation hurricane revolutions as presented in Fig. 12. When averaging over the $5^{\circ} \times 5^{\circ}$ regions of the hurricane wind fields, Q-Winds and L2B-12.5 km directions agree well with $\mathrm{H}^{*}$ Wind in nonraining regions. However, in rainy regions the L2B-12.5 km OVW algorithm retrieves cross-swath wind directions, where the $\sigma^{0}$ is dominated by isotropic rain volume backscatter (see the red "boxes" in the upper panel). On the other hand, QWinds wind directions are in good agreement with $\mathrm{H}^{*}$ Wind regardless of rain, as seen in the lower panel.

\section{c. Studies and corrections using NEXRAD}

The satellite-based measurements described above are able to sense the precipitation column in the atmosphere; however, they cannot directly resolve the vertical profile of attenuation and reflectivity. They are also limited by incomplete beam-filling and rain impact information (Owen and Long 2011a). In addition to these satellite-based observations, a high-resolution approach to measuring the three-dimensional rain reflectivity, using coastal ground-based radars, has been in progress for several years. This method utilizes the NEXRAD resources available from the U.S. National Weather Service. The NEXRAD S-band radar stations span almost the entire east coast of the United States and Gulf of Mexico. The archived data can provide useful surface rain estimates out to about $250 \mathrm{~km}$ from the shore with $2-\mathrm{km}$ spatial resolution, and within minutes of any satellite observation of these regions. For QuikSCAT studies, the beam-filling problems indicated by Fig. 2 can be minimized because the NEXRAD data consist of volumetric scan patterns that can be converted into a high-resolution radar reflectivity distribution that fills each beam of QuikSCAT radar. This allows the two-way attenuation and the volume backscatter of the Ku-band signal to be removed from the processed satellite NRCS data, leaving only the power reflected by the surface (Weissman and Bourassa 2008; Allen and Long 2005). One of the benefits of this technique is that it provides estimates of the total sea surface NRCS, the combination of the wind-driven roughness, and the rain impact roughness. The latter is observable at high rain rates $\left(10 \mathrm{~mm} \mathrm{~h}^{-1}\right)$ up to winds of $35 \mathrm{~m} \mathrm{~s}^{-1}$.

Similar to findings from previous surface-based studies (Contreras et al. 2003), an analysis of the combined QuikSCAT and NEXRAD measurements for a low wind event $\left(5 \mathrm{~m} \mathrm{~s}^{-1}\right)$ near the Texas coast shows that the surface radar cross section (NRCS) can be dominated by the rain intensity once it reaches an average of $2 \mathrm{~mm} \mathrm{~h}^{-1}$. Figures 13 and 14 show the rain intensity observed at least $50 \mathrm{~km}$ off the coastline by the Corpus Christi, Texas, NEXRAD and the surface NRCS dependence inferred from the SeaWinds scatterometer on QuikSCAT. In Fig. 13, the methodology produces collocated estimates of the spatially averaged surface rain rate (color coded in $\mathrm{dBZ}$ ) for each of the scatterometer cells (both polarizations). The H-polarized NRCS subset of these cells is plotted versus rain rate in Fig. 14. Both the original satellite NRCS data and atmospherically corrected version, to yield the total surface value, are plotted versus rain rate. The latter value represents the sum of the wind-driven surface roughness and the splash effect induced by the rain. These results indicate that the atmospheric effects are small for rain rates below $3 \mathrm{~mm} \mathrm{~h}^{-1}$ because the volume backscatter and the attenuation tend to cancel each other out. However, the mean effect of the rain-induced roughness is clearly a monotonic function of the rain intensity, causing an up to $10-\mathrm{dB}$ increase in NRCS at $10 \mathrm{~mm} \mathrm{~h}^{-1}$, and much higher as the rain rate increases to $40 \mathrm{~mm} \mathrm{~h}^{-1}$.

As the wind speed increases, the relative change in the splash-induced NRCS is not as steep. However, even at hurricane wind speeds, we find a clear dependence on 

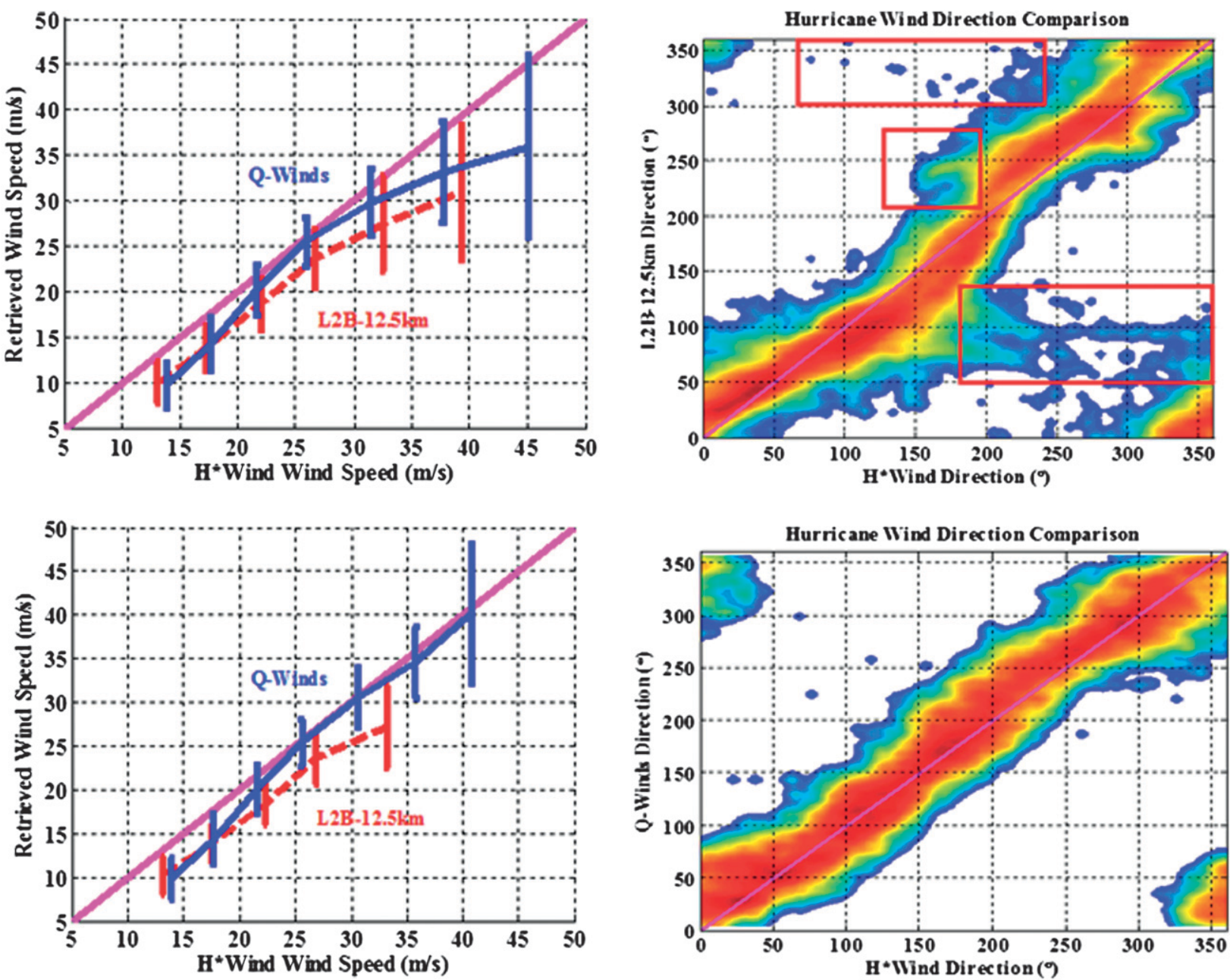

FIG. 11. Wind speed comparisons for composite of 10 QuikSCAT hurricane revolutions. Q-Winds (blue lines) and L2B-12.5 km (red) are shown. QuikSCAT retrievals (top) without rain flags and (bottom) with QRad and MUDH rain flags applied.

the rain rate. A study of this effect, when Hurricane Rita was approaching the Texas coast on 24 September 2005, was conducted. Figure 15 displays the NEXRAD rain reflectivity ( $\mathrm{dBZ})$ measured by the Houston, Texas, station (KHGX) and interpolated to an elevation of about $500 \mathrm{~m}$, with a horizontal resolution of $2 \mathrm{~km}$. The locations of the scatterometer measurement cells for NRCS (both polarizations) are overlaid; these indicate coverage over a wide range of rain intensities and wind speeds. With supporting data from the NOAA/Atlantic Oceanographic and Meteorological Laboratory (AOML)/ Hurricane Research Division it was possible to separate areas with specific ranges of wind speed magnitudes. The NRCS values for $\mathrm{H}$-pol, where the winds were estimated to be between 30 and $35 \mathrm{~m} \mathrm{~s}^{-1}$, were processed to remove the atmospheric attenuation and volume backscatter, and were then examined for their rain-rate dependence. These

FIG. 12. Wind direction comparisons to $\mathrm{H}^{*}$ Wind for 10 hurricane revolutions without rain flagging: (top) L2B-12.5 km and (bottom) Q-Winds wind directions

NRCS values, within selected rain-rate bins, were then processed with mean and standard deviations and plotted in Fig. 16. These indicate a clear increase of the NRCS with rain rate, even in these very high wind speeds where the sea surface is dominated by breaking waves, foam, and sea spray. Effects of this type are larger at the lower wind speeds. One consequence of this is that surface wind estimates, using scatterometer model functions and wind retrieval algorithms, could overestimate the wind magnitude at the higher rain rates.

\section{Summary}

The scatterometer has been demonstrated to be a major asset to oceanography, meteorology, and environmental science in general. Many of the recent major advances in satellite oceanography can be found in Liu et al. (2010). However, rain issues continue to be a cause 


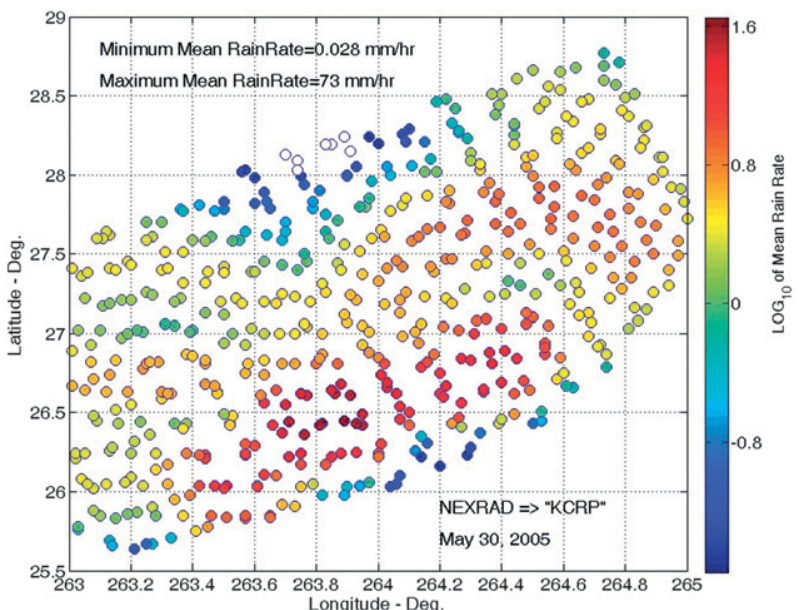

FIG. 13. Average rain intensities (log scale) at location of QSCAR cells from NEXRAD.

for concern; the relative level of interference and disruption depends on the specific area of application. As the sophistication of ocean general circulation models increase, they become increasingly sensitive to accurate surface wind stress curl forcing. In the case of climate studies, Milliff et al. (2004) has shown that missing or contaminated data lead to appreciable errors in the Sverdrup transport calculations performed for both Northern and Southern Hemispheres. There is a significant need for improved wind speed and wind stress calculations, along with more accurate rain-flagging techniques. This article provides an overview of the variety of approaches that are being actively investigated, and some specific applications where they are most successful. We show that there has been distinct progress in understanding the physics of the problem, but the solution depends on the spatial properties

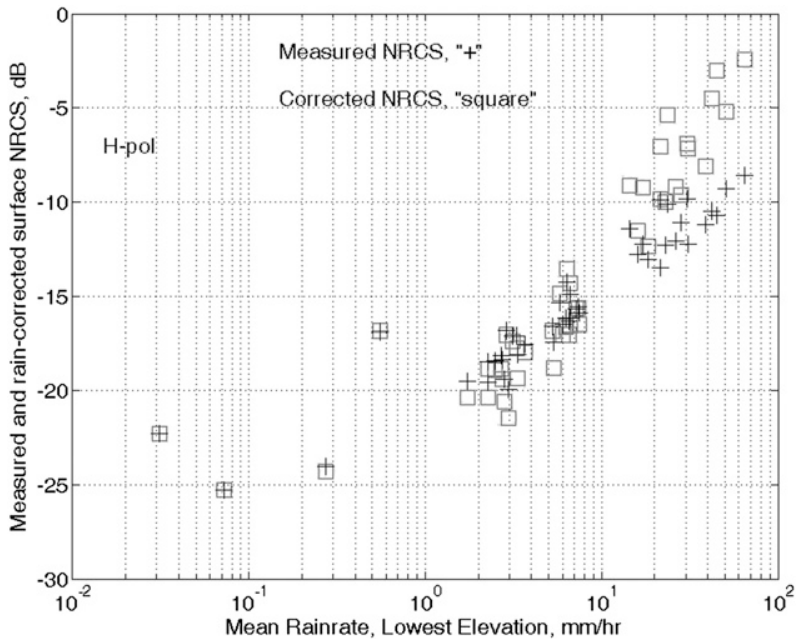

FIG. 14. H-pol-measured data and rain-corrected values to reveal surface NRCS vs average rain rate. The mean wind speed is $5.3 \mathrm{~m} \mathrm{~s}^{-1}$.

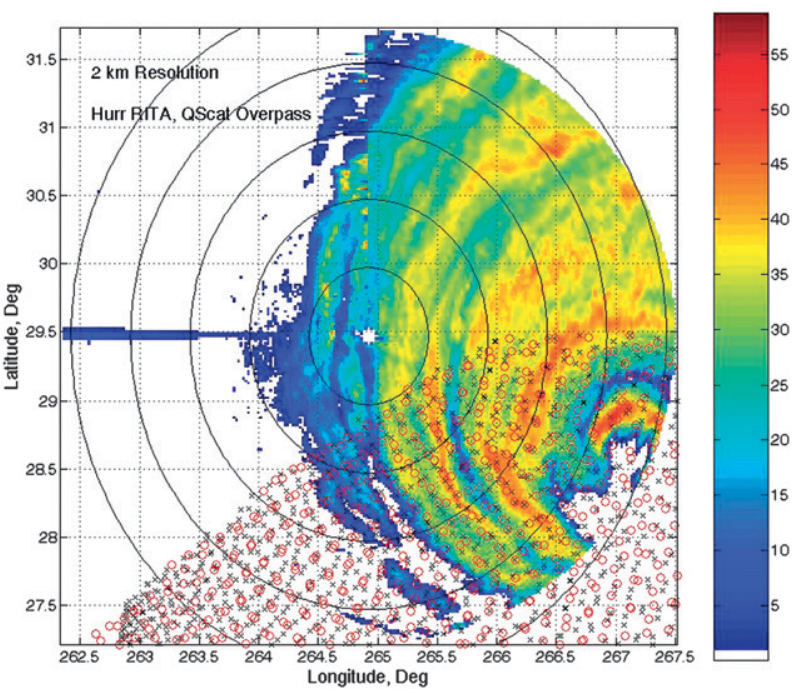

FIG. 15. Hurricane Rita: A horizontal slice of NEXRAD reflectivity; the color bar (dBZ) shows locations of the QScat level2A (NRCS) data cells located below the coastline.

of illumination, made possible with supporting data from radiometers and/or the wind retrieval algorithm. These were reviewed in Table 2 above. These programs are continuing to improve the quality of the mission data products, increasing fundamental knowledge about the atmospheric rain conditions and the sea surface impact phenomena, and preparing for the next generation of satellite scatterometers.

The history of scatterometry has dictated that the $\mathrm{Ku}-$ band radar has received most of the attention for investigating and addressing rain issues. However, the future

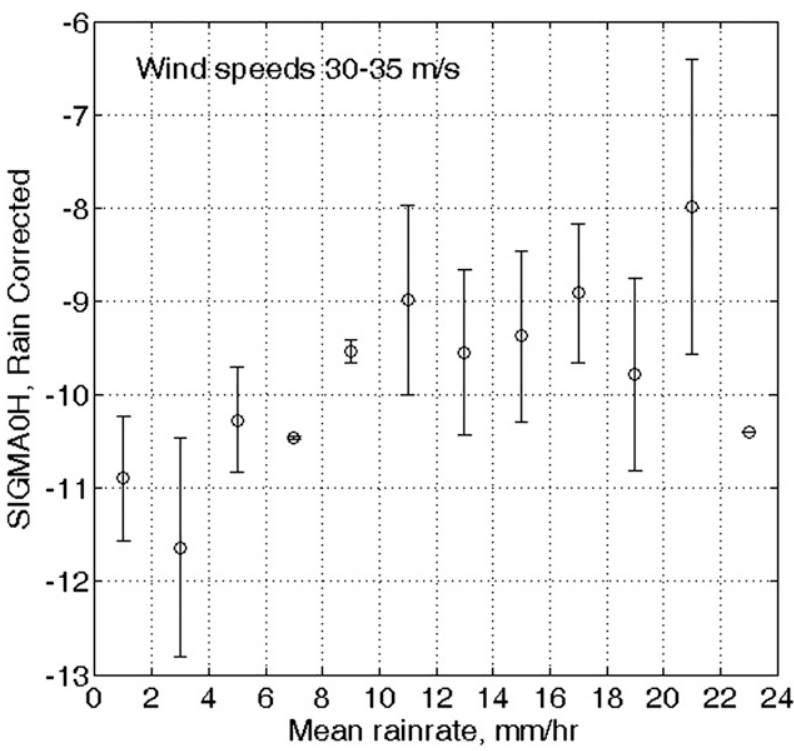

FIG. 16. Dependence of the total surface NRCS on rain intensity. Data are segmented into wind regimes and rain-rate ranges, then plotted using mean and STD error bars vs rain rate. 
spaceborne scatterometers will consist of $\mathrm{C}$ and/or $\mathrm{Ku}$ bands. In the case of ASCAT (Figa-Saldana et al. 2002), the C-band radar is unaccompanied by any other instrument, so methods for rain amelioration will depend on features of this instrument. Because of the lower raininduced backscatter and attenuation at this wavelength, the impact on this mission may not be as severe but it is still important. While there is clear evidence that atmospheric effects at $\mathrm{C}$ band are much smaller, the surface splash effect can be significant depending on wind speed and rain rate, and thus adversely affect the wind (Owen and Long 2010; Nie and Long 2007; Weissman and Bourassa 2011). Other prospects for future satellite missions would combine $\mathrm{Ku}$ - and $\mathrm{C}$-band radars, and a passive sensor with AMSR-like capabilities (e.g., Rodriguez et al. 2008; Long et al. 2009). This combination would produce a major innovation for wind measurements, more accurate correction for rain-induced artifacts, and simultaneous estimation of the collocated rain. These combined wind and rain observations will be very valuable in studying a range of weather and climate phenomena.

Acknowledgments. Much of the work reported here was supported by the Physical Oceanography Program of the National Aeronautics and Space Administration (NASA) through grants to Brigham Young University, Remote Sensing Systems, Hofstra University, the University of Central Florida, and the Center for OceanAtmospheric Prediction Studies, The Florida State University (through support by the NASA OVWST Project and the NASA/OSU SeaWinds Project). The QuikSCAT data were provided by the NASA Jet Propulsion Laboratory PO.DAAC. A portion of the research described in this paper was carried out at the Jet Propulsion Laboratory, California Institute of Technology, under a contract with the National Aeronautics and Space Administration.

\section{REFERENCES}

AGU, 2004: NSCAT and QuikSCAT: Scientific Applications. American Geophysical Union, 650 pp.

Ahmad, K. A., W. Linwood Jones, T. Kasparis, S. Vergara, I. Adams, and J. Park, 2005: Oceanic rain rate estimates from the QuikSCAT Radiometer: A Global Precipitation Mission pathfinder. J. Geophys. Res., 110, D11101, doi:10.1029/2004JD005560

_ - W. L. Jones, and T. Kasparis, 2006: QuikSCAT Radiometer (Qrad) Rainrates Level 2B Data Product. Proc. Int. Geoscience and Remote Sensing Symp., Denver, CO, IEEE, doi:10.1109/IGARSS.2006.1058.

Allen, J. R., and D. G. Long, 2005: An analysis of SeaWinds-based rain retrieval in severe weather events. IEEE Trans. Geosci. Remote Sens., 43, 2870-2878.

Andreas, E. L, 2004: Spray stress revisited. J. Phys. Oceanogr., 34, $1429-1440$
Attema, E., 1991: The Active Microwave Instrument on-board the ERS-1 satellite. Proc. IEEE, 79, 791-799.

Bliven, L. F., P. W. Sobieski, and C. Craeye, 1997: Rain generated ring-waves: Measurements and modeling for remote sensing. Int. J. Remote Sens., 18, 221-228.

Bourassa, M. A., and Coauthors, 2010: Remotely sensed winds and wind stresses for marine forecasting and ocean modeling. Proceedings of the OceanObs'09: Sustained Ocean Observations and Information for Society Conference (Vol. 2), J. Hall, D. E. Harrison, and D. Stammer, Eds., ESA Publication WPP306., doi:10.5270/OceanObs09.cwp.08.

Chang, P., and Z. Jelenak, Eds., 2008: NOAA operational satellite ocean surface vector winds-QuikSCAT follow-on mission: User impact study report. NOAA/NESDIS, 91 pp. [Available online at http://manati.orbit.nesdis.noaa.gov/SVW_nextgen/ QFO_user_impact_study_final.pdf.]

Contreras, R. F., W. J. Plant, W. C. Keller, K. Hayes, and J. Nystuen, 2003: Effects of rain on Ku-band backscatter from the ocean. J. Geophys. Res., 108, 3165, doi:10.1029/2001JC001255.

Draper, D. W., and D. G. Long, 2004a: Evaluating the effect of rain on SeaWinds scatterometer measurements. J. Geophys. Res., 109, C02005, doi:10.1029/2002JC001741.

_ and - 2004b: Simultaneous wind and rain retrieval using SeaWinds data. IEEE Trans. Geosci. Remote Sens., 42, 14111423.

Figa, J., and A. Stoffelen, 2000: On the assimilation of Ku-band scatterometer winds for weather analysis and forecasting. IEEE Trans. Geosci. Remote Sens., 38, 1893-1902.

Figa-Saldana, J., and Coauthors, 2002: The advanced scatterometer (ASCAT) on the meteorological operational (MetOp) platform. Can. J. Remote Sens., 26, 404-412.

Gaston, R., and E. Rodriguez, 2008: QuikSCAT follow-on concept study. Jet Propulsion Laboratory Publication 08-18, 66 pp. [Available online at http://trs-new.jpl.nasa.gov/dspace/bitstream/ 2014/40793/1/08-18.pdf.]

Hilburn, K. A., F. J. Wentz, D. K. Smith, and P. D. Ashcroft, 2006: Correcting active scatterometer data for the effects of rain using passive microwave data. J. Appl. Meteor. Climatol., 45, 382-398.

Hristova-Veleva, S. M., and Coauthors, 2006: Revealing the SeaWinds ocean vector winds under the rain using AMSR. Part I: The physical approach. Preprints, 14th Conf. on Satellite Meteorology and Oceanography, Atlanta, GA, Amer. Meteor. Soc., JP1.8. [Available online at http://ams.confex.com/ams/ Annual2006/techprogram/paper_104160.htm.]

Huddleston, J. N., and B. W. Stiles, 2000a: Correcting active scatterometer data for the effects of rain using passive microwave data. JPL Product Description version 2.1, 8 pp.

— and - 2000b: A multi-dimensional histogram rain flagging technique for SeaWinds on QuikSCAT. Proc. Int. Geoscience and Remote Sensing Symp. IGARSS 2000, Vol. 3, Honolulu, HI, IEEE, 1232-1234.

Laupattarakasem, P., W. L. Jones, C. C. Hennon, J. R. Allard, A. R. Harless, and P. Black, 2010: Improved hurricane ocean vector winds using SeaWinds active/passive retrievals. IEEE Trans. Geosci. Remote Sens., 48, 2909-2923.

Le Mehaute, B. L., and T. Khangaonkar, 1990: Dynamic interaction of intense rain with water waves. J. Phys. Oceanogr., 20, 1805-1812.

Liu, W. T., X. Xie, and W. Tang, 2010: Scatteometer's unique capability in measuring ocean surface stress. Oceanography from Space, V. Barale, J. F. R. Gower, and L. Alberotanza, Eds., Springer Science, 93-111. 
Long, D. G., R. Milliff, and E. Rodriguez, 2009: The TropSat mission: An observatory for mesoscale convective system processes in the global tropics. Proc. 2009 IEEE Radar Conf., Pasadena, CA, IEEE, doi:10.1109/RADAR.2009.4977098.

Lungu, T., 2006: SeaWinds science data product user's manual, version 2.0. Jet Propulsion Laboratory, California Institute of Technology Doc. D-21551, 140 pp. [Available online at ftp:// ftp.scp.byu.edu/data/seawinds/docs/SWS_SDPUG_V2.0.pdf.]

Mears, C. A., D. K. Smith, and F. J. Wentz, 1999: Development of a rain flag for QuikScat. Remote Sensing Systems Tech. Rep. 121999, 13 pp. [Available online at http://www.remss.com/ papers/tech_reports/Development_of_Rain_Flag_QuikScat.pdf.]

Melsheimer, C., W. Alpers, and M. Gade, 2001: Simultaneous observations of rain cells over the ocean by the synthetic aperture radar aboard the ERS satellites and by surface-based weather radars. J. Geophys. Res., 106 (C3), 4665-4677.

Milliff, R. F., J. Morzel, D. B. Chelton, and M. H. Freilich, 2004: Wind stress curl and wind stress divergence biases from rain effects on QSCAT surface wind retrievals. J. Atmos. Oceanic Technol., 21, 1216-1234.

National Research Council, 2007: Earth Science and Applications from Space: National Imperatives for the Next Decade and Beyond. National Academy Press, $456 \mathrm{pp}$.

Nie, C., and D. G. Long, 2007: A C-band wind/rain backscatter model. IEEE Trans. Geosci. Remote Sens., 45, 621-631.

$\longrightarrow$, and 2008: A C-band scatterometer simultaneous wind/ rain retrieval method. IEEE Trans. Geosci. Remote Sens., 46, 3618-3632.

Nielsen, S., and D. G. Long, 2009: A wind and rain backscatter model derived from AMSR and SeaWinds data. IEEE Trans. Geosci. Remote Sens., 47, 1595-1606.

Owen, M. P., and D. G. Long, 2010: Towards an improved wind and rain backscatter model for ASCAT. Proc. Int. Geoscience and Remote Sensing Symp., Honolulu, HI, IEEE, 2531-2534.

$\ldots$, and _ 2011a: Simultaneous wind and rain estimation for QuikSCAT at ultra-high resolution. IEEE Trans. Geosci. Remote Sens., 49, 1865-1878.

$\longrightarrow$, and — 2011b: M-ary Bayes estimation selection for QuikSCAT simultaneous wind and rain retrieval. IEEE Trans. Geosci. Remote Sens., 49, 4431-4444.

Plant, W. J., 1986: A two-scale model of short, wind-generated waves and scatterometry. J. Geophys. Res., 90 (C9), 10 735-10 749.

Portabella, M., and A. Stoffelen, 2001: Rain detection and quality control of SeaWinds. J. Atmos. Oceanic Technol., 18, 1171-1183.

- , and - 2002: A comparison of KNMI quality control and JPL rain flag for SeaWinds. Can. J. Remote Sens., 28, 424-430.

Rodriguez, E., B. W. Stiles, S. L. Durden, R. S. Dunbar, D. EstebanFernandez, P. S. Chang, Z. Jelenak, and S. Veleva, 2008: XOVWM: The Next-Generation Ocean Surface Vector Winds
Mission. Preprints, 28th Conf. on Hurricanes and Tropical Meteorology, Orlando, FL, Amer. Meteor. Soc., 15B.7. [Available online at http://ams.confex.com/ams/28Hurricanes/ techprogram/paper_138597.htm.]

Sienkiewicz, J., J. Von Ahn, and G. McFadden, 2006: The use of remotely sensed ocean surface at the NOAA Ocean Prediction Center. NOAA Operational Satellite SVW Winds Requirement Workshop, Miami, FL, NOAA/NESDIS/STAR. [Available online at http://manati.star.nesdis.noaa.gov/SVW_nextgen/OVW\% 20Workshop/OPC_Wind_Requirements_060506.ppt.]

Spencer, M. W., W. Tsai, and D. G. Long, 2003: High-resolution measurements with a spaceborne pencil-beam scatterometer using combined range/Doppler discrimination techniques. IEEE Trans. Geosci. Remote Sens., 41, 567-581.

Stephens, G. L., and C. D. Kummerow, 2007: The remote sensing of clouds and precipitation from space: A review. J. Atmos. Sci., 64, 3742-3765.

Stiles, B. W., and S. H. Yueh, 2002: Impact of rain on spaceborne Ku-band wind scatterometer data. IEEE Trans. Geosci. Remote Sens., 40, 1973-1983.

, and R. S. Dunbar, 2010: A neural network technique for improving the accuracy of scatterometer winds in rainy conditions. IEEE Trans. Geosci. Remote Sens., 48, 3114-3122. , and Coauthors, 2006: Revealing the SeaWinds ocean vector winds under the rain using AMSR. Part II: The empirical approach. Preprints, 14th Conf. on Satellite Meteorology and Oceanography, Atlanta, GA, Amer. Meteor. Soc., JP1.7. [Available online at http://ams.confex.com/ams/Annual2006/ techprogram/paper_104162.htm.]

_ and Coauthors, 2010: Obtaining accurate ocean surface winds in hurricane conditions: A dual-frequency scatterometry approach. IEEE Trans. Geosci. Remote Sens., 48, 3101-3113.

Stoffelen, A., and D. Anderson, 1997: Scatterometer data interpretation: Measurement space and inversion. J. Atmos. Oceanic Technol., 14, 1298-1313.

Ulaby, F. T., A. K. Fung, and R. K. Moore, 1986: Microwave Remote Sensing: Active and Passive. Vol. III, Artech House, 1120 pp.

Weissman, D. E., and M. A. Bourassa, 2008: Measurements of the effect of rain-induced sea surface roughness on the QuikSCAT scatterometer radar cross section. IEEE Trans. Geosci. Remote Sens., 46, 2882-2894.

— and -2011 : The effect of rain on ASCAT observations of the sea surface radar cross section using simultaneous 3-D NEXRAD rain measurements. Proc. IEEE Int. Geoscience and Remote Sensing Symp., Vancouver, BC, Canada, IEEE, 1171-1174.

Wentz, F. J., V. J. Cardone, and L. S. Fedor, 1982: Intercomparison of wind speeds inferred by the SASS altimeter and SMMR. J. Geophys. Res., 87 (C5), 3378-3384. 